\title{
The consequences of complex habitat loss for the New Zealand blue cod, Parapercis colias
}

\author{
Baylee Leigh Wade
}

\author{
A thesis \\ submitted to the Victoria University of Wellington \\ in partial fulfilment of the requirements for the degree of \\ Master of Science in Marine Biology
}

School of Biological Sciences

Victoria University of Wellington

2020

veroph unversiry of 


\begin{abstract}
Climate driven threats are predicted to decrease the complexity of biogenic habitats (Krumhansl et al. 2016; Teagle et al. 2017). Within temperate coastal marine environments, we know that complex macroalgal beds support more complex communities (Bruno and Bertness 2001, Norderhaug et al. 2007) through the provision of microhabitats and refuges (Anderson 2001, Kovalenko et al. 2012). Macroalgal habitats have potential interacting benefits and costs for predators, as increased macroalgal biomass supports higher richness and diversity of prey species (PérezMatus et al. 2007), but prey within these habitats might be more difficult to catch (Wilson et al. 1990). An important New Zealand fishery species, the blue cod (Parapercis colias), is a large bodied temperate reef fish found exclusively throughout the coastal waters of New Zealand. Its dependence on subtidal coastal reef environments mean that it is important to understand how a loss of complex macroalgal habitats might alter the way that blue cod forage, and how the trade-off between prey abundance and availability will affect its abundance and productivity.
\end{abstract}

This thesis aims to understand the influence of complex macroalgal habitats on $P$. colias prey availability and behaviour, on the foraging success of $P$. colias, and ultimately on $P$. colias population dynamics. Experiments were conducted using choice chambers to evaluate whether two alternate $P$. colias prey, Forsterygion lapillum and Heterozius rotundifrons, showed a preference for complex habitats with and without predation risk. Both species preferred complex habitats in the absence of predation cues, but $F$. lapillum showed a more consistent preference for complexity in response to predation risk. A mesocosm experiment was used to investigate whether the consumption rate and functional response of $P$. colias differs for these two prey types in the presence and absence of habitat complexity. Results indicated that the mobile fish prey, F. lapillum benefitted from the refuges provided by complexity and suffered lower consumption rates, whereas the sedentary crab, $H$. rotundifrons did not. Finally, using a simple population model, the trade-off between prey abundance and predation success on the population dynamics of $P$. colias with and without habitat complexity was explored. Models showed that scenarios with complex macroalgal habitats generally support more predators, and faster population growth rates than 
scenarios lacking habitat complexity. However, scenarios with complex habitats were predicted to be more sensitive to fishing pressure and have the potential to be more vulnerable to overexploitation. These results highlight the importance of understanding how habitat complexity mediates relationships between commercially important fishery species and their prey, in order to understand how habitat loss may alter their foraging success and population dynamics. 


\section{Acknowledgements}

I would firstly like to thank my supervisor Alice Rogers for her support and advice throughout my research. Her guidance and advice throughout the ups and downs of my experiments, encouragement and patience while navigating population models and her thorough proofreading and feedback on my thesis has been greatly appreciated.

I would like to acknowledge the Victoria University Coastal Ecology Lab (VUCEL) and thank the technicians, Daniel McNaughtan and John Van der Sman, for providing help with collecting resources and advice on experimental setup. I would also like to thank Grant Robinson and his fishing crew for collecting blue cod for my experiments.

To Dayanitha, Caitlin, Li and Brittany, thank you for providing much needed breaks from the lab and giving advice and encouragement along the way, especially during lab work. Also to everyone in the Marine Ecology and Ecosystem Modelling lab, thank you for your advice during various parts of my research, as well as the nice MEEM lab catch ups, which were particularly welcomed and a good morale boost during the lockdown.

Thank you to my supportive parents John and Karen, my sister Hannah and my partner Jamie. Although sometimes you may not of understood what I was talking about, you were always happy to listen and give me advice, to which I am very grateful. To my parents, thank you for your continuous love, support and constant encouragement to always do my best, this accomplishment would not have been possible without you by my side. 


\section{Table of Contents}

Abstract 2

Acknowledgements 4

Table of Contents 5

$\begin{array}{ll}\text { List of Figures } & 7\end{array}$

1. General Introduction

1.1. Habitat complexity in the marine environment 8

1.2. Macroalgal forests in temperate coastal habitats 9

$\begin{array}{ll}\text { 1.3. Threats to complex habitats } & 10\end{array}$

1.4. NZ macroalgae and coastal fisheries 11

1.5. Thesis aim 13

2. Influence of habitat complexity on $P$. colias prey availability and behaviour

2.1. Introduction 14

2.2. Methods 18

$\begin{array}{lll}\text { 2.2.1. Prey, predator and macroalgal collections } & 18\end{array}$

2.2.2. Habitat preference in the absence of predation risk 19

2.2.3. Habitat preference under potential predation risk 20

2.2.4. Habitat preference with predator stimuli 21

2.2.5. Statistical analyses 24

2.3. Results 25

2.3.1. Habitat preferences 25

2.3.2. Observed antipredator behaviour 29

2.4. Discussion 31

3. Influence of habitat complexity on $P$. colias predation

3.1. Introduction 34

3.2. Methods 39

3.2.1. Fish and invertebrate collections $\quad 39$

3.2.2. Predator consumption with and without habitat complexity 40

3.2.3. Statistical analysis 41

3.3. Results 43

3.4. Discussion 46 
4. The consequences of habitat loss for the population dynamics of $P$. colias

4.1. Introduction 49

4.2. Methods 51

4.2.1. General population model dynamics 51

4.2.2. Influence of habitat complexity 53

4.2.3. Impact of fishing mortality 56

4.2.4. Model sensitivities to prey availability 56

4.3. Results 56

4.3.1. Influence of habitat complexity 56

4.3.2. Impact of fishing mortality 57

4.3.3. Model sensitivities to prey availability 59

$\begin{array}{ll}\text { 4.4. Discussion } & 61\end{array}$

\section{General Discussion}

5.1. Overview of findings 65

$\begin{array}{ll}\text { 5.2. Limitations } & 67\end{array}$

$\begin{array}{ll}\text { 5.3. Future directions } & 67\end{array}$

$\begin{array}{ll}\text { References } & 69\end{array}$ 


\section{List of Figures}

\section{Influence of habitat complexity on P. colias prey availability and behaviour}

2.1. Experimental setup of microhabitat choice chamber

2.2. Experimental mesocosms to evaluate predatory cues 23

2.3. Frequency of $F$. lapillum and $H$. rotundifrons in microhabitats under no risk 25

2.4. Frequency of $F$. lapillum and $H$. rotundifrons in microhabitats under potential risk 26

2.5. Frequency of $F$. lapillum and $H$. rotundifrons in microhabitats under predatory cues 28

2.6. Relative frequency of antipredator behaviours ( $\% \pm S E$ ) for $F$. lapillum and H. rotundifrons

2.7. Frequency of freezing behaviour $(\% \pm \mathrm{SE})$ for each treatment 30

2.8. Frequency of defensive behaviour $(\% \pm \mathrm{SE})$ for each treatment 30

3. Influence of habitat complexity on $P$. colias predation

3.1. Relationship between prey consumption and prey density described by Holling (1959)

3.2. Experimental mesocosms to evaluate consumption rate of $P$. colias

3.3. Absolute daily consumption of $F$. lapillum and $H$. rotundifrons by $P$. colias

3.4. Number of $F$. lapillum consumed by $P$. colias

3.5. Type I Holling functions fitted to the number of F. lapillum consumed by P. colias

3.6. Number of $H$. rotundifrons consumed by $P$. colias

4. The consequences of habitat loss for the population dynamics of $P$. colias

4.1. General model schematic of multiple prey for predator population dynamics

4.2. Modelled density of predator P. colias and focal prey F. lapillum over time, with and without macroalgal habitat

4.3. Equilibrium density of $P$. colias with fishing intensity

4.4. Population growth rate of $P$. colias with fishing intensity

4.5. Proportion of maximum density (density without fishing pressure) under varied fishing mortality rates

4.6. Analysis of $P$. colias abundance with and without macroalgal habitat to explore model sensitivities to least certain parameters of prey availability 


\section{Chapter 1}

\section{General Introduction}

Ecological communities at a basic level can be viewed as linear interactions between carnivores, herbivores and plants (Fretwell 1987). These linear relationships link producers to apex predators by transferring energy along a food chain via trophic interactions and naturally interconnect to form a food web. Interactions between specific trophic levels produce certain ecosystem processes (Luck et al. 2003), which play an important role in supporting society by providing a wide range of benefits to humans in the form of ecosystem services (Barbier 2017). Resources such as food and water, as well as the provision of marine environments for tourism and recreation are examples of key services that coastal marine ecosystems provide (Daily 2013). The change in abundance of species within a food web can result in a drastic change of key ecosystem processes and subsequently ecosystem services (Holt and Loreau 2002). Therefore, the continued provision of ecosystem services is influenced by an ecosystem maintaining its current processes and function (Barbier 2017), as well as habitats maintaining complexity, to support local community dynamics and biodiversity (Godbold et al. 2011).

\subsection{Habitat complexity in the marine environment}

In the marine environment, habitat forming species support other marine organisms by modifying the physical complexity of the surrounding environment, (Jones et al. 1994, Graham and Nash 2013, Teagle et al. 2017). Complex habitats include coral reefs (Austin et al. 1980, Ménard et al. 2012), seagrasses (Bell and Westoby 1986, Unsworth et al. 2018), canopy forming macroalgae (Dayton 1985, Teagle et al. 2017) and mollusc beds (Grabowski 2004, Toscano and Griffen 2013). Each of these offer a range of benefits for their associated communities however they all provide complex structure that supports increased abundance, biodiversity (Holt 1987, Kelaher and Castilla 2004, Gratwicke and Speight 2005) and increased trophic interactions, which result in longer 
food chains and ultimately support more complex food webs (Alvarez-Filip et al. 2011). Highly complex habitats provide increased surface area and niche space which support more species and individuals (Bruno and Bertness 2001, Gratwicke and Speight 2005). Increased surface area and structural complexity is important in structuring diverse and abundant assemblages within the understory and canopy of macroalgal forests (Hauser et al. 2006) and seagrass meadows (Heck et al. 1977), as well as within crevices on coral reefs (Luckhurst and Luckhurst 1978, Walker et al. 2009). Habitat complexity provides refuges for prey which support the presence of juveniles and small-bodied species that are often preyed upon by larger organisms (Hixon and Beets 1993, Almany 2004, Wen et al. 2013). Increased refuge availability reduces the competition between prey to seek refuge and can increase prey survival, preventing extinction when populations reach low densities (Murdoch and Oaten 1975, Lannin and Hovel 2011).

\subsection{Macroalgal forests in temperate coastal habitats}

Rocky reef environments in both subtidal and intertidal habitats on temperate coastlines are often dominated by species of canopy-forming large brown macroalgae, predominantly from the order Laminariales (Dayton 1985, Steneck et al. 2002). These species of macroalgae provide high structural complexity, from the holdfast that anchors the algae to the substrate, (often the most complex microhabitat, Arnold et al. 2016), to the shade forming canopy provided by the macroalgal blades. The complexity of macroalgal habitats, composed of the macroalgae itself and the varying relief of the surrounding submerged rocks, offers a large amount of substrate for understory algae and invertebrates to colonise (Hauser et al. 2006, Cacabelos et al. 2010). When compared to habitats with low habitat complexity, macroalgal habitats are highly dynamic and support high primary productivity (Brady-Campbell et al. 1984, Reed et al. 2008), increased abundance of invertebrates and fish (Pérez-Matus et al. 2007) and increased recruitment of associated species (Carr 1994). On temperate reefs, we know that complex macroalgal beds support more complex communities (Bruno and Bertness 2001, Norderhaug et al. 2007) through the provision of microhabitats and refuges (Anderson 2001, Kovalenko et al. 2012). Studies so far show that the 
mechanism of a refuge in macroalgal habitats appears to be dependent on the presence and quantity of habitat structure (Anderson 2001, Hesse et al. 2016), rather than the ratio between crevice and prey body size observed in tropical coral reef environments (Hixon and Beets 1993, Rogers et al. 2014). Artificial plants have been used in various experiments in an attempt to standardise the effect of macroalgal habitat complexity (Gotceitas and Colgan 1989, Hauser et al. 2006) and they were successful in finding a positive relationship between complexity and abundance. However, we don't yet have a good understanding of how macroalgal degradation alters the flow of energy through the food web and influences the productivity of higher trophic levels.

\subsection{Threats to complex habitats}

Warmer sea temperatures (Edwards and Hernández-Carmona 2005), increased storms and extreme weather patterns (Meehl et al. 2000, Easterling et al. 2000, Byrnes et al. 2011) and eutrophication and acidification (Russell et al. 2009, Sunday et al. 2017) have contributed to a decline in biodiversity and the quality of biogenic habitats. These threats degrade and disturb the quality, abundance and recruitment of biogenic species including macroalgae (Alestra and Schiel 2015, Filbee-Dexter et al. 2016), corals (Munday 2004, Albright et al. 2010) and seagrasses (Fraser et al. 2014, Thomson et al. 2015). Degraded habitats, and a reduction in habitat complexity, can have knock on effects such as decreased biodiversity (Jones et al. 2004), abundance and growth of associated communities (Rogers et al. 2014). These negative impacts alter species compositions and the interactions between species (Crowder and Cooper 1982, Teagle and Smale 2018), which ultimately reduce ecosystem function and structure (Hawkins et al. 2009). Changing land use and increased terrestrial erosion and runoff is increasing the addition of sediments and chemical pollutants into coastal habitats and has also been identified as a cause of degradation and a change in species composition for habitats such as seagrass meadows, macroalgal beds and coastal coral reefs (Weber et al. 2006, Alestra and Schiel 2015, Unsworth et al. 2018). Temperate reef systems are specifically threatened by tropicalization, the movement of new or invasive species better suited for the warmer environment (Vergés et al., 2014; Gianni 
et al., 2017), as well as overfishing of apex predators (Tegner and Dayton 2000), which increase the abundance of secondary herbivorous consumers, threatening the community composition and dynamics of macroalgal-dominated temperate reef systems (Steneck et al. 2002, Myers and Worm 2003). A decline in the quantity and quality of canopy-forming species also clears space for less structurally complex turf or shrub algae to colonise and overgrow coralline crusts (Connell 2003) replacing and preventing the regeneration of macroalgae (Filbee-Dexter and Wernberg 2018). Degradation of biogenic habitats reduces complexity and alters prey availability, leading to shortened food chains and ultimately altering the trophic structure (Hempson et al. 2017).

\subsection{New Zealand macroalgae and coastal fisheries}

Habitat forming macroalgae are complex habitats that prevail along rocky coastlines in New Zealand, with the giant kelp (Macrocystis pyrifera) dominating coastal marine environments broadly in the southern North Island and the South Island (Ministry for Primary Industries 2017), and common kelp (Ecklonia radiata) rapidly growing around the North Island (Schiel 1990). The thermal tolerance of these species limits their distribution in New Zealand (Hay 1990) however they both sustain productive and diverse ecosystems (Mann 1973, Reed et al. 2008). Complex macroalgal habitats offer protection to many reef fishes and benthic invertebrates, among which are often important commercial fisheries species (Bologna and Steneck 1993). The diversity and abundance of reef fishes has been shown to increase with increased macroalgal presence and density with both $M$. pyrifera and complex macroalgae, the common flapjack (Carpophyllum maschalocarpum) (Pérez-Matus and Shima 2010). Macroalgal habitats are important for juveniles with snapper (Pagrus auratus), a highly sought after fisheries species, using macroalgal reef fringes as nurseries (Ross et al. 2007). Biogenic reefs provided by $M$. pyrifera, E. radiata and C. maschalocarpum support a diverse range of commercially important coastal finfish species in New Zealand, such as butterfish (Odax pullus), blue cod (Parapercis colias), blue moki (Latridopsis ciliaris), red moki (Cheilodactylus spectabilis) and tarakihi (Nemadactylus macropterus) (Schiel 1990, Pande and Gardner 2009, Ministry for Primary Industries 2017). Macroalgal 
habitats also support invertebrate fisheries such as kina (Evechinus chloroticus) and paua (Haliotis iris) (Schiel 1990, Ministry for Primary Industries 2017). In New Zealand, we know that a loss of kelp in temperate coastal reef environments can affect the assemblage of benthic predators, influencing the distribution and abundance of the associated prey species (Hesse et al. 2016). When comparing fish assemblages within Ecklonia radiata and a barren habitat, prey are more susceptible to predation in barren habitats than within macroalgal habitats (Hesse et al. 2016).

An increase in climate driven threats to macroalgal habitats has the potential to decrease habitat complexity, and therefore decrease diversity and productivity of associated species, causing a trophic cascade through the rest of the food web (Byrnes et al. 2011). With anthropogenic effects predicted to reduce the quality and quantity of macroalgae (Krumhansl et al. 2016; Teagle et al. 2017), it is critical that we understand how a loss of habitat complexity will impact their ecosystem structure and function, to manage for long term sustainability of ecosystem services (MacDiarmid et al. 2013). Marine ecosystem services including fisheries, tourism and aquaculture are vital for New Zealand. The commercial fishing industry is worth more than $\$ 4$ billion and is a significant contributor to New Zealand's economy (Williams et al. 2017). Understanding the associations between coastal fisheries species and macroalgal reef habitats in New Zealand is important for fisheries management and predicting how they might be affected by habitat modification in the future. New Zealand fisheries are currently managed using models that assess the maximum sustainable yield of a stock, however models don't tend to take into account climate change, or habitat considerations that might affect the dynamics of fisheries populations (Armstrong et al. 2008).

\section{Parapercis colias}

An important New Zealand fishery species, the blue cod (Parapercis colias), is a large bodied temperate reef fish found exclusively throughout the coastal waters of New Zealand. P. colias is most abundant south of the Cook Strait (Carbines, 1998) and is a 
sought after recreational and commercial inshore finfish. Landings of $P$. colias combined over all stocks during the most recent publicly reported fishing year of 2016/2017 were 2150 tonnes (Fisheries New Zealand 2018). The stocks on average have a combined annual value of $\$ 36$ million for the fishing industry (Williams et al. 2017). They are one of the most commonly landed finfish species in the South Island, with certain stocks having exhibited declines in recent years (Ministry for Primary Industries 2014). The diet of $P$. colias largely depends on the availability of prey in the local habitat and they are mostly opportunistic benthic carnivores that feed diurnally (Jiang and Carbines 2002). They reside in sub tidal, slow flowing habitats such as rocky reef fringes, gravel and sandy bottoms or within biogenic structures such as mussel beds and macroalgal forests, often in coastal areas shallower than 150m (Anderson et al., 1998; Carbines and Mckenzie, 2004). We don't explicitly know how a loss of habitat complexity may alter the way that top predators like $P$. colias forage, and how important complex habitats are for mediating predator prey relationships in New Zealand. The dependence of $P$. colias on the shallow coastal reef environments, dominated by macroalgae, mean it is important to understand how the population dynamics of $P$. colias may change with potential macroalgal habitat loss.

\subsection{Thesis aims}

This thesis aims to understand how a change in macroalgal habitat complexity and a change in prey vulnerability will then affect the associated community, energy transfer and the population dynamics of $P$. colias. Specifically, in Chapter 2, I aim to understand whether $P$. colias prey prefer complex macroalgal microhabitats under no perceived predation risk, and whether they use habitat complexity to avoid predation. In Chapter 3 , I evaluate whether macroalgal habitat complexity influences the consumption rates and/or the shape of the functional response curve for the $P$. colias and two of its prey species. Finally, in Chapter 4, using a simple population model I explore the trade-off between prey abundance and predation success on the population dynamics of $P$. colias with and without macroalgal habitat complexity. 


\section{Chapter 2}

\section{Influence of habitat complexity on $P$. colias prey availability and behaviour}

\subsection{Introduction}

The dynamics of prey populations are influenced by predators either directly consuming prey or changing their behaviour (Werner et al. 1983) and distribution (Clark et al. 2003). The success of prey populations in the marine environment is largely determined by the ability of individuals to avoid predation or to adopt defensive morphological and behavioural traits to escape predators. Growth rates of prey populations can be influenced by the abundance of predators, with higher abundances attributed to higher prey mortality and slower population growth (Hereu et al. 2005). Predators therefore induce avoidance tactics in prey that reduce their vulnerability, but can limit their individual growth (Werner et al. 1983) due to reduced foraging. Reduced foraging by prey populations in response to the presence and abundance of predators can have knock-on effects on lower trophic levels resulting in trophic cascades (Grabowski 2004).

When faced with predators, prey strive to avoid a predatory encounter and increase their probability of survival. To avoid high densities of predators, prey might shift their range and distribution to lower risk environments with less predators and/or less opportunity for predators to attack (Heithaus et al., 2009). This results in prey avoiding habitats containing high abundances of predators (Preisser et al. 2005) or seeking refuge in microhabitats within complex habitats that are difficult for predators to access. In the presence of predatory cues, fish are often seen to primarily flee and seek shelter within nearby available refuges created by the structural complexity of habitats (Almany 2004, Ménard et al. 2012). This can sometimes limit prey to less productive foraging areas and reduce their individual feeding activity and energy intake (Milinski and Heller 1978, Werner et al. 1983, Heithaus et al. 2009). Predation risk is often greatest for small individuals whose predators have a large gape size (Hart and Hamrin 
1990), and therefore complex habitats are particularly important for small individuals and juveniles of larger species (Wilson et al. 1990). Complex habitats fulfil the role of nurseries for juveniles of species by providing shelter and food when species are small and most vulnerable (Guidetti 2000). Complex microhabitats are also commonly productive feeding grounds as they tend to support an increased abundance of potential prey than less complex habitats (Heck and Crowder 1991, Chaves et al. 2013). The structure of complex habitats also offer protection from wave action and high flowing currents in coastal environments which can be important in reducing energetic costs (Parsons et al. 2018).

In shallow, temperate marine ecosystems, canopy forming macroalgae are the foundation of structurally complex habitats (Steneck et al. 2002). Macroalgae have an important role in providing food through detrital production (Feehan et al. 2018), reducing sediment deposits (Wernberg et al. 2005) and reducing current flow (Rosman et al. 2007). Macroalgal habitats offer nursery grounds for juveniles (Tegner and Dayton 2000) and provide refuge from predators (Wilson et al. 1990, Anderson 2001). Three different structures of canopy forming macroalgae provide a refuge: the holdfast, stipe and blades. The holdfast consists of branching haptera, and provides space between branches for macrofauna and meiofauna to colonise and use as a refuge (Hauser et al. 2006). The stipe of the plant provides a refuge for assemblages of sessile invertebrates to directly attach to (Leclerc et al. 2015) whereas the blade of the plant provides the most surface area for colonisation and mostly provides a microhabitat for highly mobile fauna (Jørgensen and Christie 2003).

Within macroalgal reef habitats, highly complex microhabitats are comprised of the 3dimensional structure of both the macroalgal blades and the varying relief of submerged rocks, holdfasts and cobble substrate, which creates a large amount of surface area for a variety of prey (Hauser et al. 2006, Cacabelos et al. 2010). Small sized fishes are generally associated with heterogenous habitats that offer high refuge (Hixon and Beets 1993), whereas the lower macroalgal bed and substrate is a 
microhabitat that small crabs are known to inhabit (Anderson et al. 2005). P. colias is an opportunistic benthic carnivore that feeds diurnally, and their diet largely depends on the availability of prey in the local habitat (Jiang and Carbines 2002). Found throughout the shallow coastal waters of New Zealand, $P$. colias specifically resides in sub tidal, slow flowing habitats such as rocky reef fringes, mussel beds, macroalgal forests, gravel or sandy bottoms, (Anderson et al. 1998, Carbines and Mckenzie 2004). Diet studies show that crustaceans, molluscs and small fish are the main components of the P. colias diet (Russell and Leigh 1983, Jiang and Carbines 2002).

Prey require an ability to detect a potential threat to elicit short term behavioural responses and in aquatic environments, prey primarily detect predatory cues using visual and olfactory senses (Hazlett and McLay 2005, Kim et al. 2009). Prey use visual and tactile cues to recognise position and potential distance from heterospecifics (Smolka et al. 2011). Chemical cues released as alarm cues, or in response to conspecifics being injured by predation (Chivers and Smith 1998, Jacobsen and Stabell 2004), as well as predator odours in the form of kairomones (Kats and Dill 1998) allow prey to sense the presence of a predator through olfaction.

Fish and invertebrates have different strategies for avoiding predation, due to differences in morphology and mobility. Shifting habitats and using refuges or cryptic mechanisms can reduce the likelihood of prey encountering predators. Both fish and crustaceans use burrowing as an antipredator mechanism. Burrowing is particularly common in small prey that lack other defensive mechanisms (McLay and Osborne 1985, Magnhagen and Forsgren 1991). Camouflage is also a widespread morphological adaptation where prey use markings to resemble the colour and pattern of the surrounding habitat (Endler 1984, Todd et al. 2006, Troscianko et al. 2016), thereby reducing their risk of detection (Stevens and Merilaita 2009). Fish, due to their high mobility within the water column, use the shelter provided by macroalgal blades to avoid predators through the mechanisms of a visual and physical refuge (Wilson et al. 1990, Guidetti 2000). However, invertebrates such as small crabs are unable to swim 
within entire macroalgal habitats and may instead burrow into the substrate and lower section of the macroalgal plants (Hauser et al. 2006, Cacabelos et al. 2010). Crustaceans also defend themselves against predators with weapons or deterrents such as long, spiny antennae (Barshaw et al. 2003, Patek and Oakley 2003) and extended claws (Field 1990). Hard shells in small crabs can absorb energy under impact and protect them from being crushed in the mouth of predators (Strathmann 1981). Prey with effective defensive structures necessitate longer handling time for predators and as a result, may be rejected, with a preference for conspecifics or heterospecifics that are easier to attack and consume (Boulding 1984, Gochfeld 2004). The effectiveness of these defensive structures in crabs likely outweigh their reduced mobility.

\section{Chapter aim}

Declining macroalgal biomass globally due to the cumulative effects of climate change (Teagle et al. 2017) is leading to a reduction in desirable highly complex microhabitat which may force some prey populations to choose less complex habitats with fewer refuges when faced with predation risk. The purpose of this study was to investigate whether prey of the temperate predator the blue cod, Parapercis colias, prefer complex macroalgal microhabitats under no perceived predation risk, and whether they use habitat complexity to avoid predation. To investigate this, fish, invertebrates and macroalgae that are commonly found and accessible from the rocky reef environment around the coastal Wellington region were collected as model species. The common triplefin Forsterygion lapillum is a small reef fish and the big handed crab Heterozius rotundifrons a small crab found in rocky coastal habitats around New Zealand, often within cobble, rocks and macroalgae. The study specifically investigates whether these species prefer microhabitat complexity under no perceived risk, a potential predation risk and with variations of visual and olfactory predatory stimuli from $P$. colias. Three experiments were conducted at Victoria University of Wellington Coastal Ecology Laboratory (VUCEL). The first experiment tested whether prey prefer more complex microhabitats and display any antipredator behaviour without the influence of predator cues. The second experiment tested whether prey microhabitat 
choice and antipredator behaviour was influenced by a simulated predator risk. The last experiment aimed to understand the importance of visual and olfactory cues from P. colias, on habitat preferences and antipredator behaviour of their prey. Three variations of an experiment using only a visual cue, only an olfactory cue and both visual and olfactory cues together.

\subsection{Methods}

\subsubsection{Prey, predator and macroalgal collection}

F. lapillum were collected by hand nets, aided by snorkel and SCUBA, from the infralittoral zone at two Wellington rocky shore sites: Kau Bay (latitude: $-41.287623^{\circ}$, longitude: $174.829033^{\circ}$ ) and Point View Breaker Bay (latitude: $-41.344759^{\circ}$, longitude: $\left.174.820649^{\circ}\right) . H$. rotundifrons were collected by turning over rocks in the intertidal zone of Kau Bay during low tide. Both prey species were collected between February and September 2019. The common flapjack, Carpophyllum maschalocarpum was selected to represent a complex macroalgal habitat for the two prey species. It is a common brown macroalgae found sub-tidally within rocky reef habitats around New Zealand. It provides microhabitats within its broad, flat blades, which create dense branches within the water column. C. maschalocarpum blades were collected by hand from Kau Bay during low tide between June and September 2019. F. lapillum and $H$. rotundifrons were stored separately in flowing seawater tanks $(59 \times 30 \times 30 \mathrm{~cm})$, with a layer of cobble on the bottom ( $2 \mathrm{~cm}$ thick). C. maschalocarpum blades were kept in a flowing seawater tank before and after trials. Macroalgae were replaced in habitat choice experiments whenever they showed signs of degradation. Both prey species were fed a diet of crushed mussel every 3 days. The predator Parapercis colias was collected by local fishermen from the Cook Strait, Wellington in July 2019 using cod pots. Predators were maintained in outdoor plastic $1000 \mathrm{~L}$ tanks with flow through seawater. 
During trials each individual prey was only used once in each experimental variation. All F. lapillum were between $4-5 \mathrm{~cm}$ in length, with both sexes used under an assumption that sex would not influence microhabitat preference. The $H$. rotundifrons used were between 2-4 cm wide and sex also wasn't assumed to be a factor in microhabitat preference. $31 \mathrm{~F}$. lapillum and $33 \mathrm{H}$. rotundifrons were trialled under no perceived risk, $29 \mathrm{~F}$. lapillum and $33 \mathrm{H}$. rotundifrons were used in trials with a potential predator stimulus, and for trials under visual, olfactory and both predation stimuli 15 each of $F$. lapillum and $H$. rotundifrons were used per experimental variation.

\subsubsection{Habitat preference in the absence of predation risk}

This experiment was conducted between July and August 2019. It was designed to investigate whether $F$. lapillum and $H$. rotundifrons prey species prefer complex microhabitats and, or display any antipredator behaviour in the absence of a perceived predation risk from $P$. colias. A choice chamber was constructed with four microhabitat assemblages varying in complexity and refuge availability; cobble ( $C$; low), cobble and rock ( $\mathrm{CR}$; intermediate), cobble and C. maschalocarpum (CK; intermediate), cobble and rock as well as C. maschalocarpum (CRK; high). A plexiglass arena separated into 4 chambers was used for the trials (seen in Figure. 2.1). Each chamber had one of the four microhabitat configurations whose position was assigned randomly and changed between trials. The rocks chosen were flat with dimensions of $15 \mathrm{~cm} \times 10 \mathrm{~cm} \times 4 \mathrm{~cm}(\mathrm{~L} \times$ $\mathrm{W} \times \mathrm{H}$ ) and a single frond of $\mathrm{C}$. maschalocarpum was used for both the CK and CRK habitat configurations. For each trial a single prey individual was randomly selected and introduced into a PVC pipe in the centre of the arena. Following 1 minute of acclimation, the pipe was lifted to allow the individual to choose a habitat. The trial was observed for 5 minutes in total and the habitat in which the individual spent the most time was recorded as the preferred habitat. If prey did not spend any time within any habitat, the selection was noted as no microhabitat choice. At the end of each 5 min trial, the individual was removed, and fresh seawater was added to the tank for 30s before the microhabitat in each chamber was changed based on the random assignment, and another trial commenced. 
During the trial, counts and descriptions of any antipredator behaviour were noted to investigate whether prey actively reduce predation risk even under no perceived risk. Based on the behaviour observed, two categories of antipredator behaviour were defined for each prey species. For F. lapillum, the categories were defined as defensive behaviour of crypsis/camouflage to the cobble or macroalgae and freezing (freezing for at least 10 seconds or not moving at all during the trial). For $H$. rotundifrons, the categories were defined as behaviour that involved freezing (freezing for at least 10 seconds or not moving at all during the trial) and defensive behaviour (extending pincers). Multiple behaviours were often observed in a single trial by a single individual and therefore counts of each behaviour during the 5 minute trial were recorded.

\subsubsection{Habitat preference under potential predation risk}

This experiment was conducted between August and September 2019. It built upon the previous trial to investigate whether the prey use complex habitats more, or indeed less in the presence of some perceived risk. To evaluate this, the same protocol was used as in the experiment with no risk, but here, following acclimation, as the pipe was lifted, a pebble attached to string was dropped into the water $\sim 1 \mathrm{~cm}$ above the prey. The fast movement of the pebble approaching the prey attempted to stimulate a stress response in the prey, similar to when a predator approaches prey. During the trials to investigate microhabitat choice of prey under no stimulus, it was found that prey would generally decide on a preferred habitat within the first 2 minutes. Therefore, in this experiment, trials were run for 2 minutes in total. The pebble was left in place for the duration of the trial. In this trial, the first microhabitat that prey moved to was recorded as the microhabitat preference. If prey visited more than one microhabitat within the course of the trial then the preference was determined by the habitat in which most time was spent. Again, if prey did not spend any time within any habitat, the selection was noted as no microhabitat choice. During experiments investigating the microhabitat choice of $F$. lapillum and $H$. rotundifrons under stress stimulus, the same protocol as in the experiment with no stimulus was used to determine if there are recurring patterns of antipredator behaviour when under predation risk, or whether they differ. 


\subsubsection{Habitat preference with predator stimuli}

These experiments were conducted in September 2019 and investigated the influence of visual and olfactory predatory stimuli from $P$. colias on the habitat preference of their prey. The same protocol was used as in previous experiments, with the addition of one of three predator stimuli treatments; a visual stimulus only, an olfactory stimulus only, and the combination of both visual and olfactory stimuli together. The same choice chamber arena was used in this study, but here it was placed inside a larger $1000 \mathrm{~L}$ circular plastic tank containing a single $P$. colias. As for the perceived risk treatment, trials were run for 2 minutes, with the habitat preference defined as the first and only habitat chosen, or the habitat in which the prey spent most time. Again, if prey did not spend any time within any habitat, the selection was noted as no microhabitat choice. As before, antipredator behaviours in two different categories were recorded as counts. Three predator stimuli were captured as follows:

\section{Visual stimulus only}

The experimental arena was housed within a larger circular tank containing $P$. colias, which was uncovered and setup so that opening was $10 \mathrm{~cm}$ above the water level of the outer tank (seen in Figure 2.2). This allowed the prey to view P. colias in the outer tank but the water containing the olfactory cue from $P$. colias was unable to flow into the experimental tank.

\section{Olfactory stimulus only}

The experimental arena was housed within the larger circular tank containing $P$. colias, but it was covered with shade cloth on all exposed sides except the opening on the top. It was positioned such that the top of the tank was $\sim 1 \mathrm{~cm}$ below the water level of the outer circular tank (seen in Figure 2.2 ) allowing the water containing the $P$. colias and its cue to flow into the experimental tank. Prey were able to detect the olfactory stimulus, but could not see the predator. 


\section{Visual and olfactory stimuli combined}

The experimental arena was housed, uncovered within the larger circular tank containing $P$. colias and positioned such that the top of the tank was $\sim 1 \mathrm{~cm}$ below the water level of the outer circular tank (seen in Figure 2.2). This allowed the olfactory cue from $P$. colias to flow into the experimental tank while simultaneously allowing the prey to view $P$. colias in the outer tank.

(A) No Risk

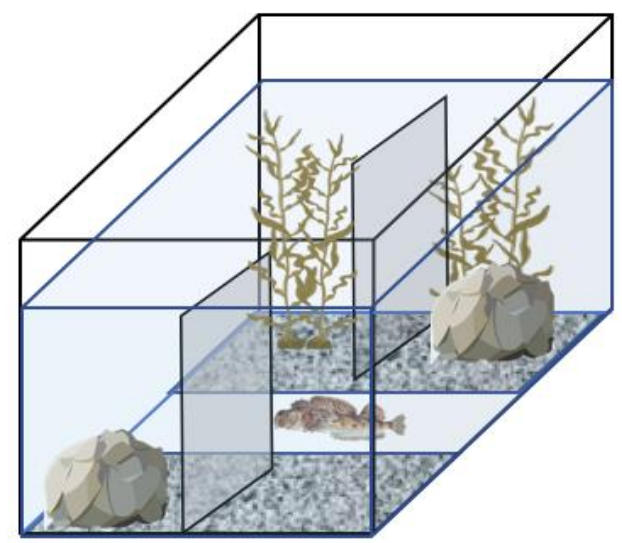

(B) Potential

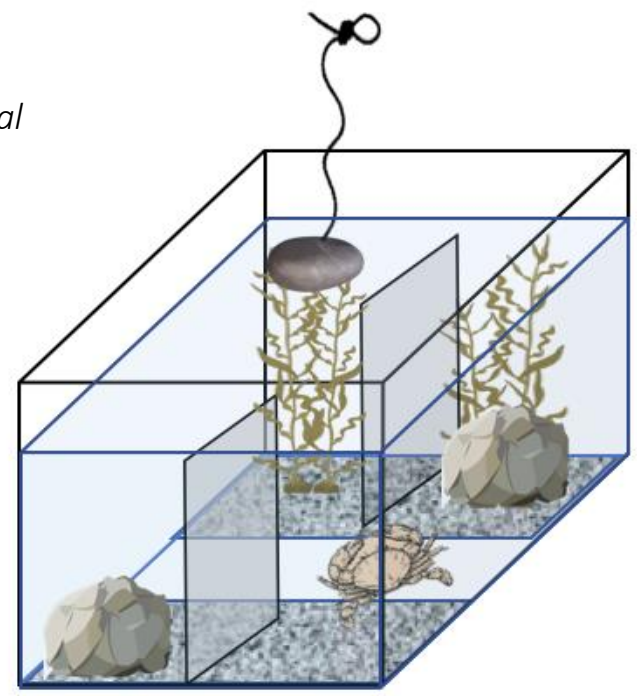

Figure 2.1: Experimental setup to investigate whether the prey items $F$. lapillum and $H$. rotundifrons prefer complex microhabitats under no perceived risk as well as under potential predation risk. A) Shows the experimental arena, $300 \mathrm{~mm} \times 600 \mathrm{~mm} \times 300 \mathrm{~mm}$. Also the position of the two dividers separating the arena into four chambers. Each supporting a different microhabitat assemblage of either cobble; cobble and rock; cobble and C. maschalocarpum; cobble, rock and C. maschalocarpum.. B) Shows the same arena used for the experiment with potential risk, however also showing the location of the pebble used to stimulate a stress response in prey. 


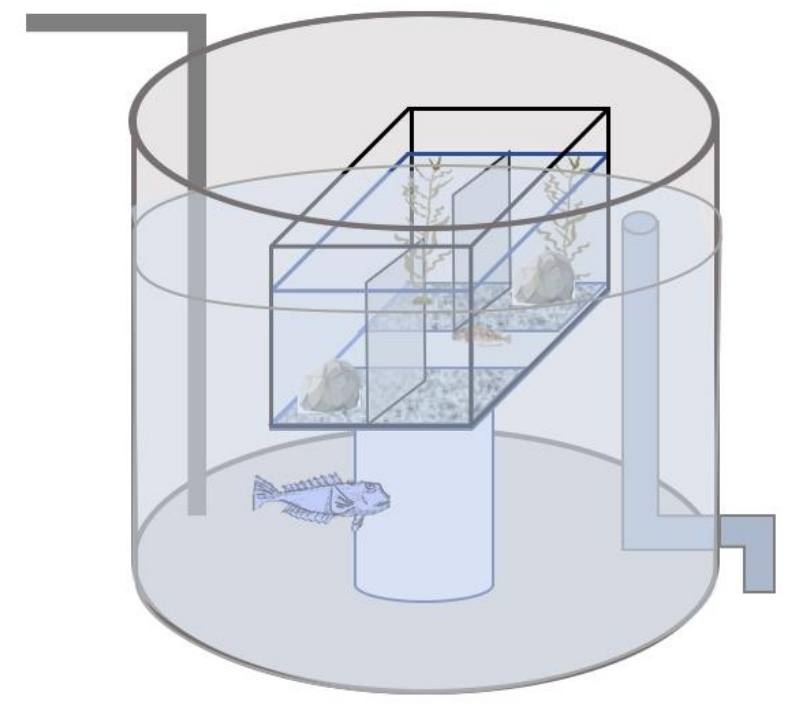

(A) Visual Stimulus
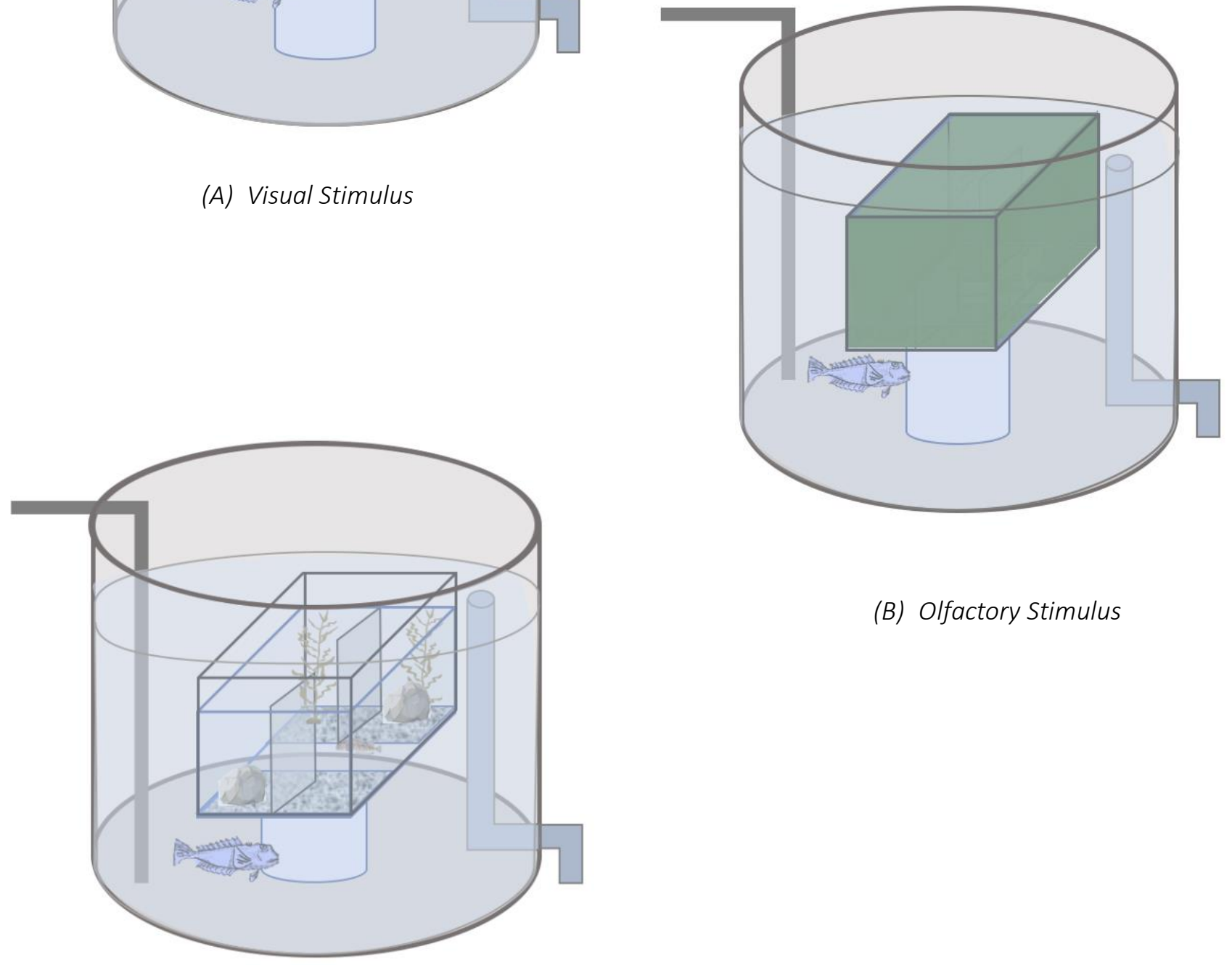

(B) Olfactory Stimulus

(C) Visual and Olfactory Stimulus

Figure 2.2: Experimental setup to investigate whether the prey items $F$. lapillum and $H$. rotundifrons select complex microhabitats under predatory stimuli from $P$. colias. Each diagram shows the location of the arena within the larger outer tank $(1000 \mathrm{~L}, 1100 \mathrm{~mm} \times 650 \mathrm{~mm})$ containing $P$. colias. (A) With visual stimulus: the water from the larger tank couldn't flow into the arena and the prey were only able to use the visual stimulus of $P$. colias. (B) With olfactory stimulus: to prevent visual stimulus, the arena was covered with shade cloth (green) on all sides except the top and was below the water level of the larger tank, allowing olfactory cues to flow into the arena. (C) With both stimuli, the arena was below the water level of the larger tank to allow for olfactory cues, and was uncovered to allow prey to observe $P$. colias. 


\subsubsection{Statistical Analyses}

Multinomial Exact Tests were conducted separately to test whether F. lapillum and $H$. rotundifrons prefer complex microhabitats during experiments under no perceived risk, a potential predation risk and visual and olfactory predatory stimuli, or whether the observed counts within each microhabitat were equal. As each Multinomial Exact Test was performed comparing counts of individuals in five categories $(C=$ cobble; $C R=$ cobble and rock; $\mathrm{CK}=$ cobble and kelp (C. maschalocarpum); $\mathrm{CRK}=$ cobble, rock and kelp (C. maschalocarpum) and NC = no choice made), the expected counts were calculated by dividing the number of individuals in each experiment $(n)$ by the number of categories (5). For experiments where observed counts significantly deviated from an equal distribution, Pairwise Tests were conducted to see whether the counts within specific microhabitat categories deviated significantly from the expected count in an equal distribution. As multiple pairwise tests were performed at the same time, I applied the Bonferroni correction to the significance test. Statistical analyses were conducted in R ( $R$ Core Team 2018) using the package XNomial (Engels 2015) to perform Multinomial Exact Tests.

Frequency of combined antipredator behaviour, as well as the individual antipredator behaviours (freezing, defensive) were analysed over pooled treatments (under no predation risk, potential predation risk and under a visual stimulus, olfactory stimulus and both stimuli together) and over treatments separately for both F. lapillum or $H$. rotundifrons together and in isolation. Generalized linear models (GLM) specifying a Poisson error distribution and a log linear link function were used to compare the frequencies of antipredator occurrence. The observed counts for each antipredator behaviour, for each treatment, were added to the model with the number of trials as an offset, as the number of trials differed between treatments. Statistical analyses for GLM were conducted using the base package in R (R Core Team 2018). 


\subsection{Results}

\subsubsection{Habitat preferences}

\section{No predation risk}

The average time taken for $F$. lapillum to select a microhabitat under no predation risk was $52.26 \mathrm{~s} \pm 7.62$ (mean $\pm \mathrm{SE}$ ) and for $H$. rotundifrons was $61.82 \mathrm{~s} \pm 11.30$ (mean $\pm \mathrm{SE}$ ). The observed counts of microhabitats chosen under no predation risk deviated from an equal distribution for both $F$. lapillum (Multinomial Exact Test, $P<.001$, Figure 2.3) and $H$. rotundifrons (Multinomial Exact Test, $P<.04$, Figure 2.3). Both prey showed a significant choice for complex microhabitats in the absence of any predation risk with both $F$. lapillum and $H$. rotundifrons preferentially selecting the cobble, rock and kelp (CRK) microhabitat more than expected (Multinomial Pairwise Test, $P<.05$, Figure 2.3).
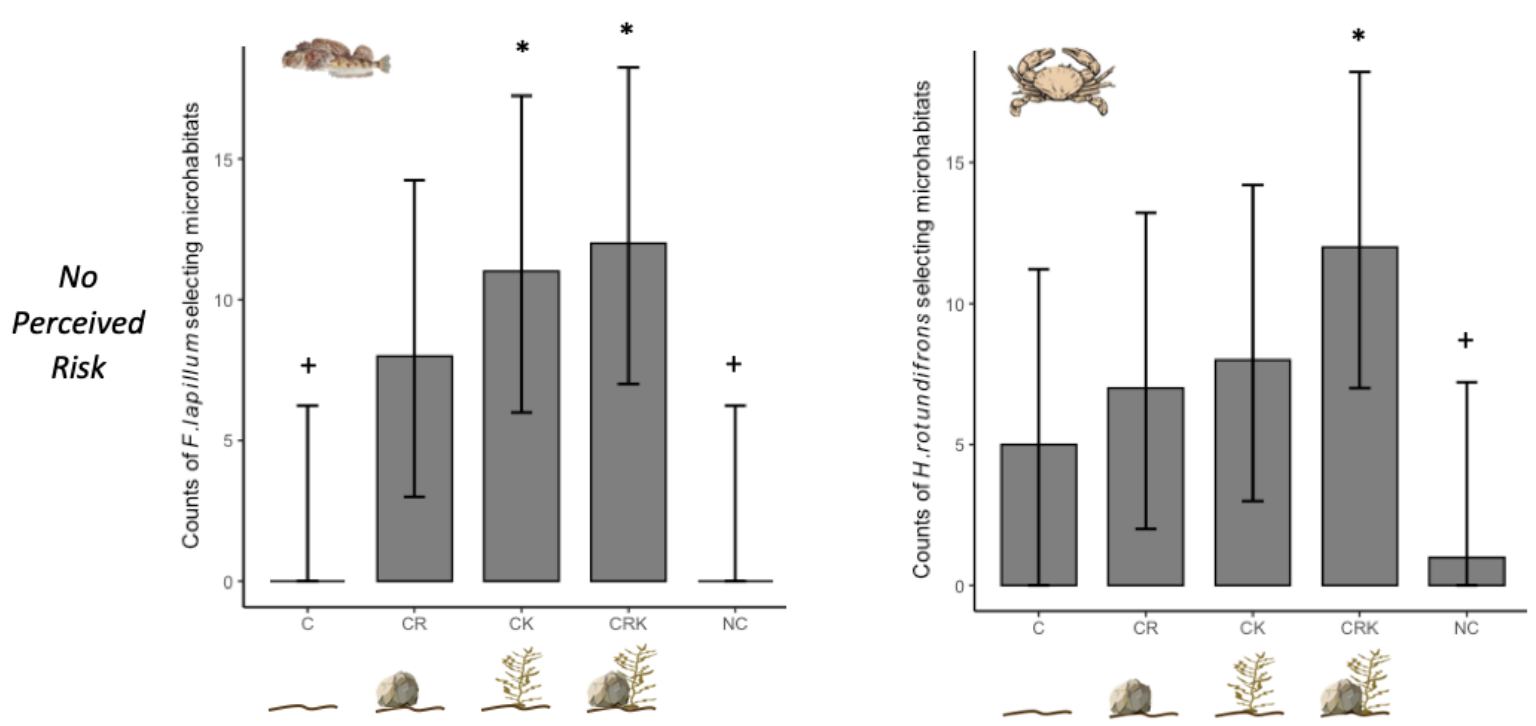

Figure 2.3: Frequency counts (count $\pm 95 \%$ confidence interval) of $F$. lapillum and $H$. rotundifrons that selected each microhabitat when under no predation risk. Microhabitats are as follows: $\mathrm{C}=$ cobble; $\mathrm{CR}=$ cobble and rock; $\mathrm{CK}=$ cobble and kelp (C. maschalocarpum); $\mathrm{CRK}=$ cobble, rock and kelp (C. maschalocarpum) and $\mathrm{NC}=$ no choice made. Also displaying microhabitats that were selected significantly higher than expected $(*)$ or significantly lower than expected $(+)$ if all were selected equally in the Exact Multinomial Test $(p<0.05)$. 


\section{Potential predation risk}

The observed counts of microhabitats chosen under a potential predation risk deviated from an equal distribution for both $F$. lapillum (Multinomial Exact Test, $P<.001$, Figure 2.4) and $H$. rotundifrons (Multinomial Exact Test, $P<.05$, Figure 2.4). F. lapillum significantly preferred to use complex microhabitat in the presence of potential predation risk and preferentially selected the cobble, rock and kelp (CRK) microhabitat more than expected (Multinomial Pairwise Test, $P<.001$, Figure 2.4). $H$. rotundifrons did not show a significant preference for a microhabitat, however they show a potential preference for any microhabitat complexity over no microhabitat at all (Figure 2.4).
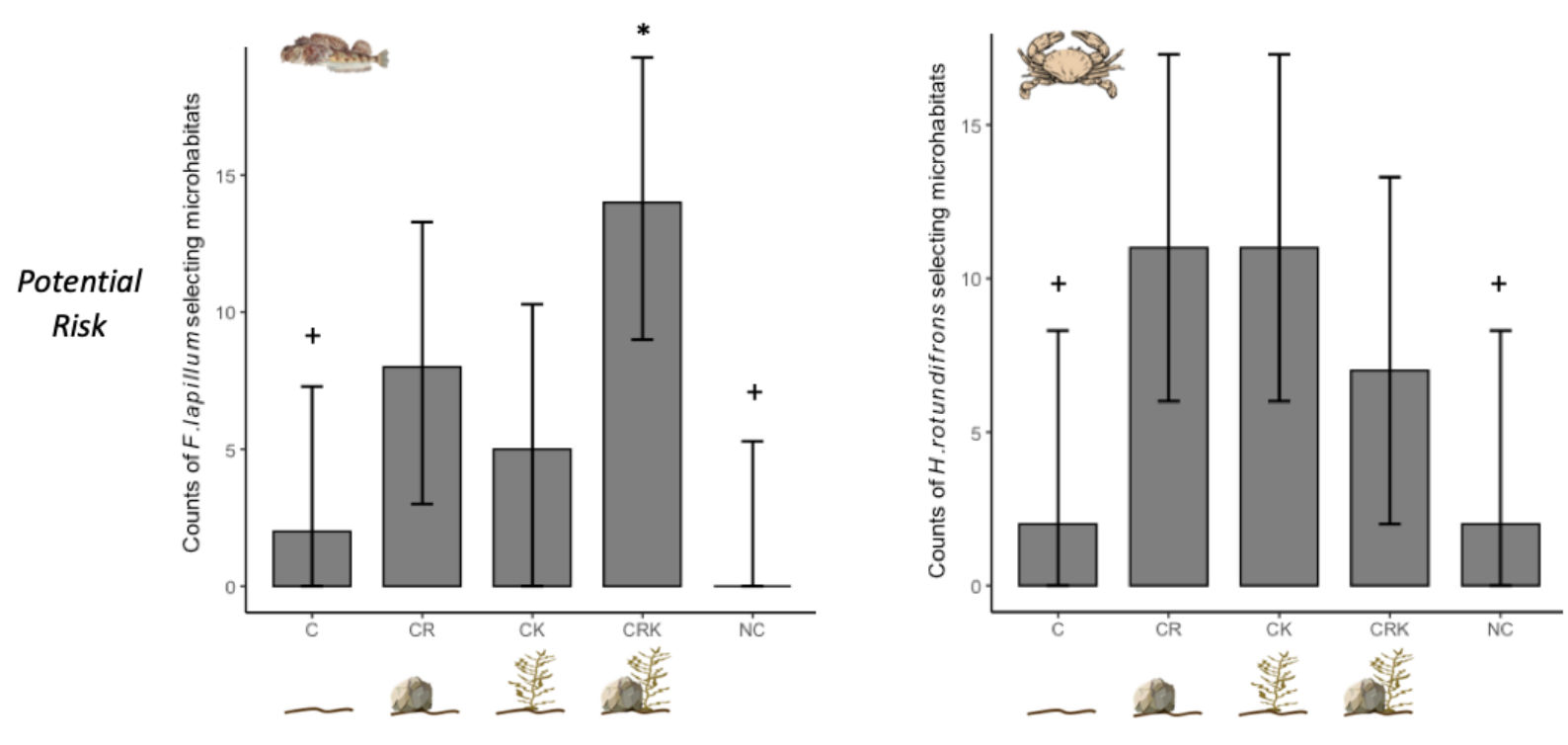

Figure 2.4: Frequency counts (count $\pm 95 \%$ confidence interval) of $F$. lapillum and $H$. rotundifrons that selected each microhabitat when under potential risk. Microhabitats are as follows: $C=$ cobble; $C R=$ cobble and rock; $\mathrm{CK}=$ cobble and kelp ( $C$. maschalocarpum); $\mathrm{CRK}=$ cobble, rock and kelp ( $C$. maschalocarpum) and $N C=$ no choice made. Also displaying microhabitats that were selected significantly higher than expected $(*)$ or significantly lower than expected $(+)$ if all were selected equally in the Exact Multinomial Test $(p<0.05)$. 


\section{Stimuli from $P$.colias}

The observed counts of microhabitats chosen under all treatments of predatory stimuli did not statistically deviate from an equal distribution for both F. lapillum and $H$. rotundifrons (Figure 2.5). Although no distributions of any variation of predatory stimuli significantly deviated from an equal distribution, there were some nonsignificant trends in the habitat choices of the two prey species. F. lapillum were more inclined to preferentially chose more complex microhabitats than $H$. rotundifrons in general. They chose the most complex microhabitat, an assemblage of cobble, rock and kelp or the intermediate microhabitats of cobble and kelp or cobble and rock at higher frequencies, whereas $H$. rotundifrons tended to choose cobble and rock or cobble and kelp and failed to choose any microhabitat as refuge under a visual stimulus (Figure 2.5). 

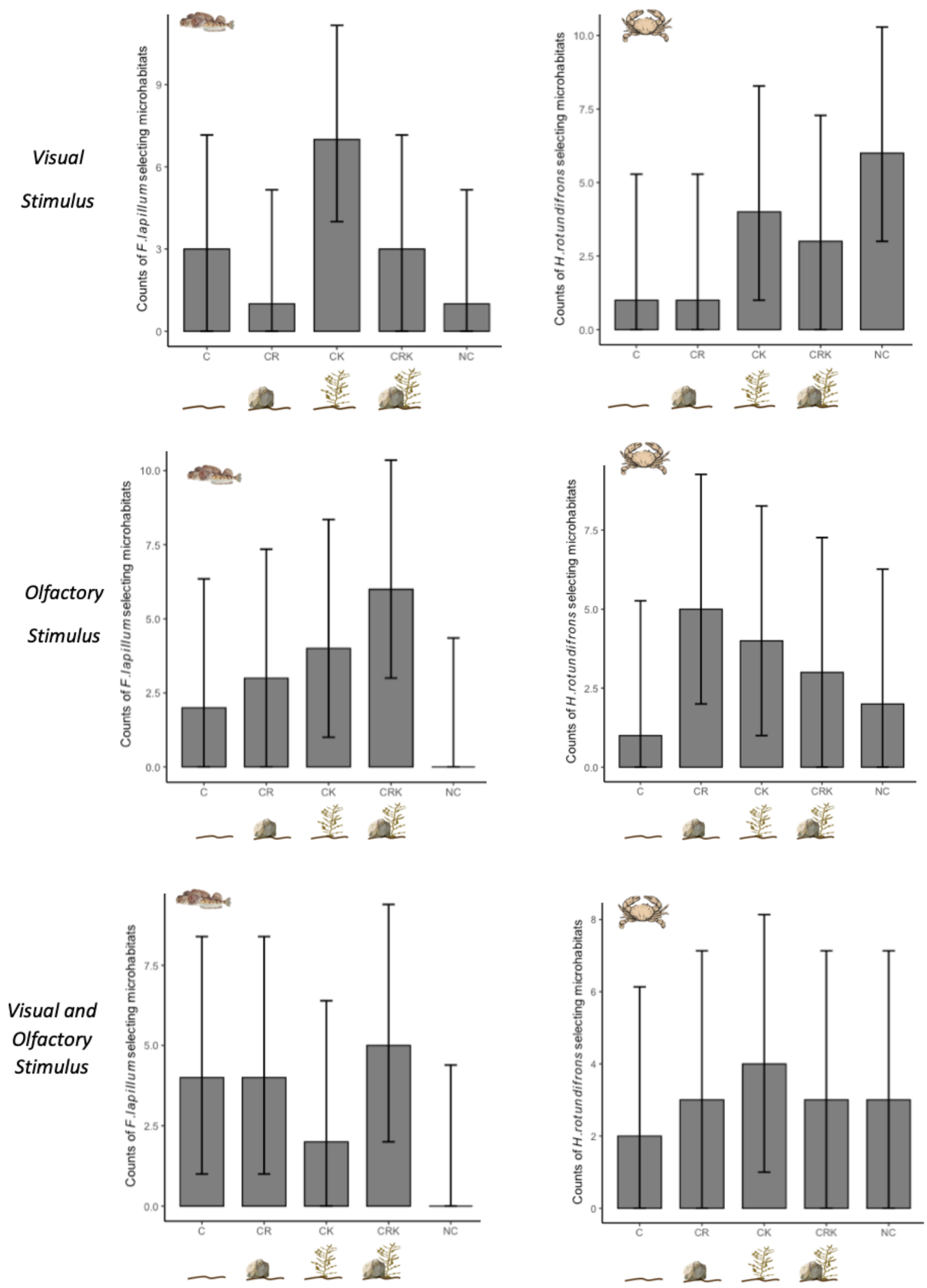

Figure 2.5: Frequency counts (count $\pm 95 \%$ confidence interval) of $F$. lapillum and $H$. rotundifrons that selected each microhabitat when under visual stimulus, olfactory stimulus and both stimuli. Microhabitats are as follows: $\mathrm{C}=$ cobble; $\mathrm{CR}=$ cobble and rock; $\mathrm{CK}=$ cobble and kelp ( $\mathrm{C}$. maschalocarpum); $\mathrm{CRK}=$ cobble, rock and kelp (C. maschalocarpum) and NC = no choice made. 


\subsubsection{Observed Antipredator Behaviour}

The relative frequency of freezing behaviour, combined over all treatments, was observed significantly more for $H$. rotundifrons $(t=1.04$, $\mathrm{df}=16, P<.01$, Fig. 2.6). However the relative frequency of defensive behaviour, combined over all treatments, was not significantly different between species (Figure 2.6). Freezing behaviour was observed significantly more for $H$. rotundifrons under a visual stimulus $(t=1.79, \mathrm{df}=1$, $P<.05$, Fig. 2.7). No other significant differences in freezing behaviour, across treatments, were found between the two species (Figure 2.7). Defensive behaviour was not observed to be significantly different for either species under all treatments (Figure 2.8).

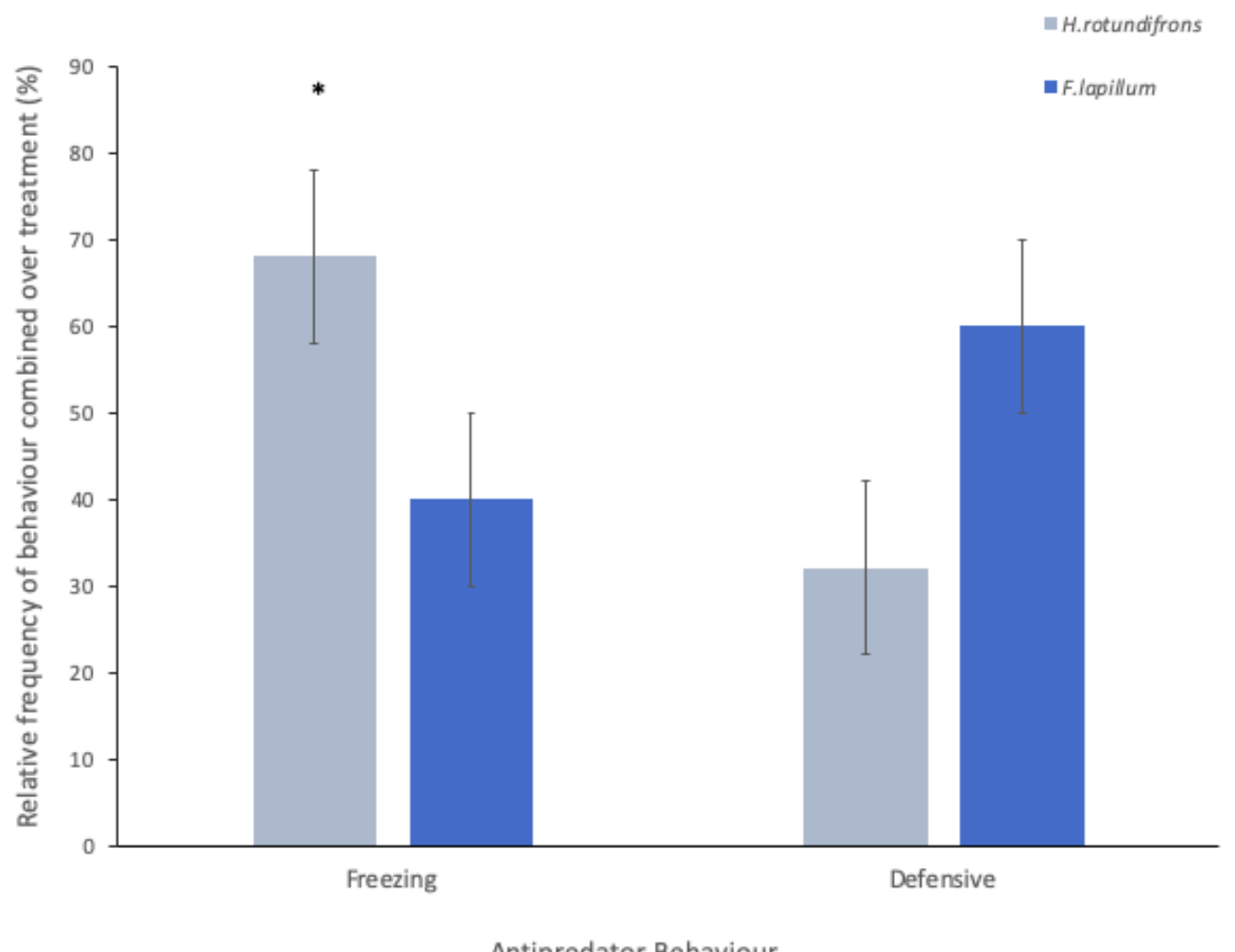

Figure 2.6: Relative frequency of each antipredator behaviour ( $\% \pm \mathrm{SE})$ for $F$. lapillum and $H$. rotundifrons. Significant differences $(P<0.05)$ relative to different prey are denoted by ${ }^{*}$. 


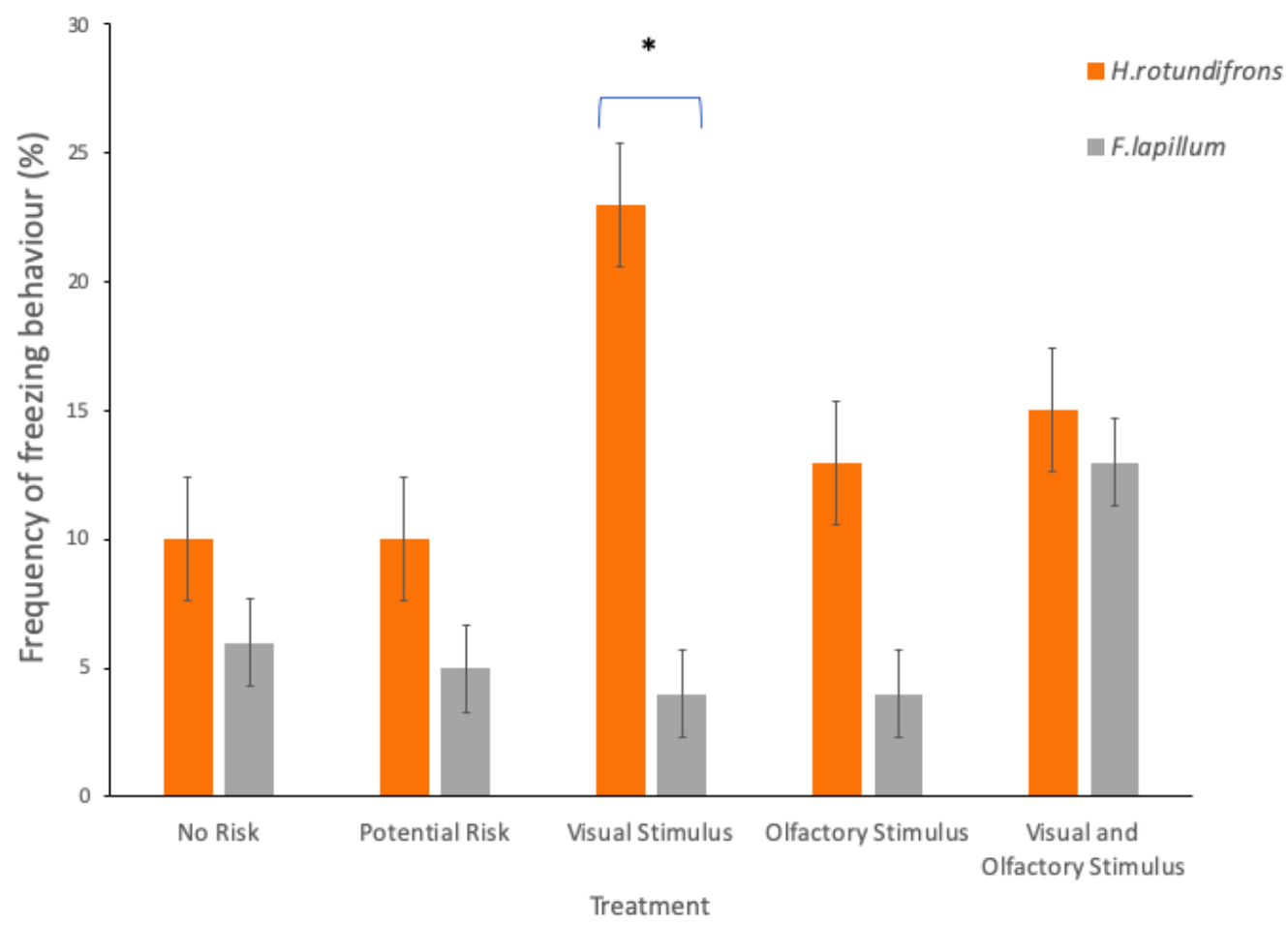

Figure 2.7: Frequency of freezing behaviour ( $\% \pm \mathrm{SE}$ ) for each treatment; when under no predation risk, potential predation risk and under a visual stimulus, olfactory stimulus and both stimuli together. For both $F$. lapillum and $H$. rotundifrons. Significant differences $(P<0.05)$ relative to different prey are denoted by*.

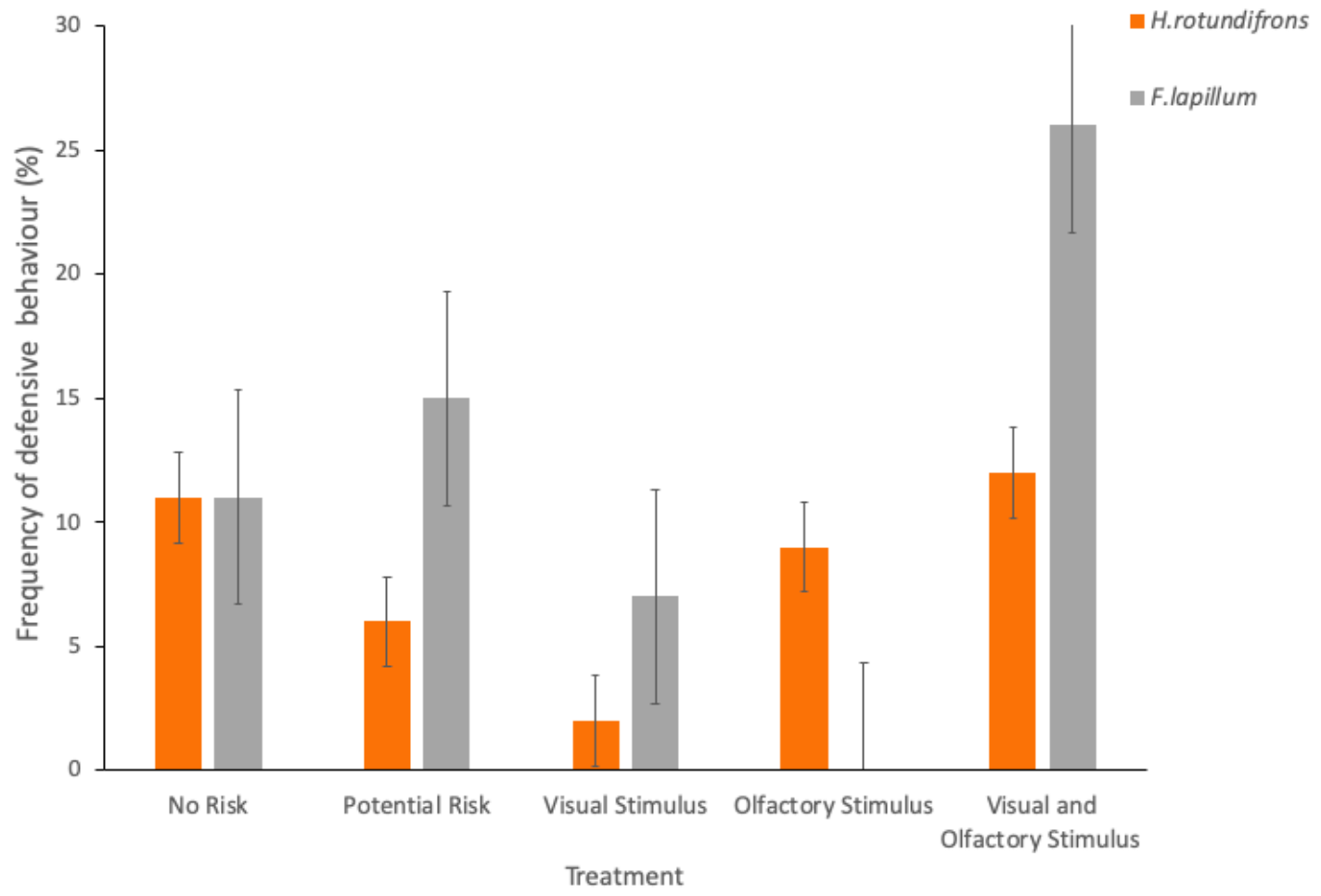

Figure 2.8: Frequency of defensive behaviour ( $\% \pm \mathrm{SE}$ ) for each treatment; when under no predation risk, potential predation risk and under a visual stimulus, olfactory stimulus and both stimuli together. For both $F$. lapillum and $H$. rotundifrons. 


\subsection{Discussion}

It is evident that prey species $F$. lapillum and $H$. rotundifrons have a preference for complex macroalgal microhabitats in the absence of perceived predation risk. This may be due to the refuges provided complex microhabitats. However, the preference for complexity was only found under no risk and potential risk scenarios, and not in the presence of any true predatory stimuli from $P$. colias. This study also suggests that $H$. rotundifrons displays freezing behaviour under predation risk, particularly under a visual predation stimulus. The preference for complex microhabitats observed when prey had no perceived predation risk suggests complex microhabitats containing macroalgae may aid small temperate reef fish and mobile invertebrates to passively reduce detection by nearby predators. Even when predation risk is low, certain species may prefer complex microhabitats as it allows them to undertake specific predator avoidance responses (Scharf et al. 2006) such as burrowing observed in both species. Yet the preference for microhabitat complexity is likely for a range of benefits in addition to predator avoidance; complex microhabitats are good sources of food and shelter (Bruno and Bertness 2001, Chaves et al. 2013). Inhabiting open areas such as cobble or sand exposes prey to predators but also provides less food (Heck and Crowder 1991, Chaves et al. 2013) and less shelter from high flowing currents (Parsons et al. 2018). Prey may therefore be better placed to inhabit complex habitats for their full range of benefits and opportunities.

Variable environmental conditions such as turbidity and low light availability can result in ambiguous predatory cues in the marine environment (Wisenden 2000, Ranåker et al. 2012). Where prey detected a potential predation risk, but no predatory stimulus was present, F. lapillum predominantly used complex habitats whereas $H$. rotundifrons used varying levels of complexity to hide within. The difference in the reliance of the two species on complex habitats, in response to potential risks, suggest that shelter provided by complex macroalgal habitats is important for small bodied fish similar to $F$. lapillum (Wilson et al. 1990, Guidetti 2000). Choosing complex microhabitats like 
macroalgae is likely the best form of protection from large-bodied predators for $F$. lapillum (Warfe and Barmuta 2004, Susannah et al. 2011). By contrast, H. rotundifrons regularly displayed behaviours of freezing in response to predatory cues. These results suggest that instead of using complex macroalgal habitats for refuge, small crustaceans use robust morphology, in the form of extended pincers, as a mechanical defence. Increasing the gape size needed for a predator to swallow its prey can limit consumption rates (Persson et al. 1996) and H. rotundifrons has been shown to exhibit the defensive behaviour of extended pincers in other studies (Field 1990, Hazlett and McLay 2000) and did so here at low frequencies in response to all treatments. However freezing was observed predominantly under visual stimulus by $P$. colias, and moderately across all other treatments, suggesting when $H$. rotundifrons can see its predator, they further rely on their hard shell, to prevent predators from consuming them (Barshaw et al. 2003, Patek and Oakley 2003).

In response to predatory cues from $P$. colias, $F$. lapillum and $H$. rotundifrons showed similar trends in habitat preference as in other trials but differences were not statistically significant. It is possible that due to the experimental set up whereby P.colias was able to swim 360 degrees around the experimental arena, this may have confounded the results. Prey might, for example have been simply selecting the microhabitat furthest away from the predator when the visual cue was available, and not the microhabitat that they would choose under true predation risk. It is likely that experiments with just the olfactory stimulus from $P$. colias wouldn't be affected by this, but noting the predators position at the time of microhabitat selection or fixing its location could disentangle the microhabitat choice of $F$. lapillum and $H$. rotundifrons when it is truly effected by predatory cues of $P$. colias.

Herbivorous and omnivorous fish are more abundant in habitats with high macroalgal complexity when compared to less complex habitats (Parsons et al. 2016) and the abundance of small reef fish, similar to F. lapillum, positively increases with macroalgal cover (Willis and Anderson 2003). Macroalgal habitats with mixed stands of 
M. pyrifera, C. maschalocarpum and C. retroflexa, common New Zealand macroalgal species, are associated with higher abundances of $F$. lapillum when compared to single macroalgal species or the absence of macroalgae (Pérez-Matus and Shima 2010). High refuge availability is necessary for F. lapillum and for small fish species, as the diet of piscivorous predators is gape limited and the small size of $F$. lapillum puts them at risk of higher mortality than larger bodied prey fish (Persson et al. 1996). Although many mobile species are found within macroalgal habitats, not all rely on these habitats to avoid predation. Crustaceans such as small demersal crabs are also found at higher abundance within the rocky substrate and the understory of macroalgal forests of $M$. pyrifera (Hines 1982). However crustaceans burrow into substrate and use mechanical defensive mechanisms in response to predators, as was evident in the results of this study. The lower mobility of crabs in comparison to small fish, may mean that effectiveness of these antipredator tactics may outweigh the need for crustaceans to hide within macroalgal plants and that with reduced macroalgal complexity, crustaceans can still use the same defensive antipredator behaviours (Hazlett and McLay 2000, Bouwma and Hazlett 2001). 


\section{Chapter 3}

\section{Influence of habitat complexity on $P$. colias predation}

\subsection{Introduction}

Increased physical structure of a biogenic habitat increases microhabitat availability and niche space, allowing predators and prey to coexist (Crowley 1978). Species richness and abundance increase with increasing habitat complexity because there is greater surface area available for species to inhabit (Bruno and Bertness 2001, Hauser et al. 2006). Complex habitats can reduce predator efficiency by impeding predator movement (Gregor and Anderson 2016) and providing refuges for prey that prevent or reduce their detection (Murdoch and Oaten 1975, Lannin and Hovel 2011, Clemente et al. 2013). The physical structure of a biogenic habitat can vary spatially and temporally, resulting in changes to its complexity and the microhabitat availability that it offers for the community (Langellotto and Denno 2004). Reduced habitat quality due to habitat destruction (Teagle et al. 2017) and climate change (Edwards and Hernández-Carmona 2005), reduces the complexity available to mediate predator-prey relationships. Low habitat complexity then has knock on effects of reduced species richness (Gratwicke and Speight 2005, Airoldi et al. 2008), biodiversity (Tilman et al. 2017, Teagle and Smale 2018) and refuge space available for prey (Rogers et al. 2014).

Complex habitats can offer physical refuges that are inaccessible to predators and therefore provide protection for prey (Hixon and Beets 1993, Almany 2004, Wen et al. 2013). When presented with reliable cues of predation risk, prey increase competition for refuge space within microhabitats (Hixon and Beets 1993) and decrease foraging activity (Kim et al. 2009) to reduce the chance of an interaction with a predator. 
On tropical coral reefs, high complexity habitats provide numerous cracks, crevices and holes that provide predation refuges and support increased abundance (Gratwicke and Speight 2005) and biodiversity (Jones et al. 2004) of the community (Ménard et al. 2012). The cumulative effects of climate change, notably warming and ocean acidification threaten tropical coral reefs, and are causing a flattening of reef structure around the world (Alvarez-Filip et al. 2009, Pelejero et al. 2010, Kiessling and Simpson 2011). Using models that explicitly capture the effects of refuge loss on tropical coral reefs, it has been shown that declining habitat complexity results in reduced fisheries productivity, driven by decreased abundance and growth of large-bodied predators (Rogers et al., 2014). Degradation of tropical coral reefs alters prey availability and leads to shortened food chains, ultimately altering the trophic structure (Hempson et al. 2017).

On temperate reefs, we know that complex macroalgal beds support higher species diversity and abundance (Bruno and Bertness 2001, Norderhaug et al. 2007) through the provision of microhabitats and refuges (Anderson 2001, Kovalenko et al. 2012). However, we don't yet have a good understanding of how macroalgal degradation alters the flow of energy through the food web and influences the productivity of higher trophic levels. Macroalgal habitats mediate predator prey interactions by providing a refuge for prey species much like coral reefs do (Anderson 2001, O’Brien et al. 2018). However, studies so far show that refuge availability in macroalgal habitats is dependent on the presence and quantity of habitat structure (Anderson 2001, Hesse et al. 2016), rather than the specific abundance and size of reef crevices as in tropical reef environments (Hixon and Beets 1993, Rogers et al. 2014). Artificial plants have been used in various experiments in an attempt to standardise the effect of macroalgal habitat complexity (Gotceitas and Colgan 1989, Hauser et al. 2006) and they were successful in finding a positive relationship between complexity and abundance. However, there are a lack of studies that use artificial habitats to standardise macroalgal complexity and then quantify its effect on predator prey interactions and the productivity of higher trophic level organisms. 
Although its overall benefits are well documented, habitat complexity has complex, non-linear impacts on the foraging success of predator species (Gotceitas and Colgan 1989). In high complexity habitats, the foraging success of predators might be reduced because prey can hide in refuges (Orth et al. 1984, Wilson et al. 1990, Carroll et al. 2015), whereas in low complexity habitats prey are more exposed and their chances of survival are lower (Crowder and Cooper 1982, Norbury and van Overmeire 2019). However, the relationship between habitat complexity and the foraging success of predators is not necessarily linear because prey abundance can also change with habitat complexity (Hauser et al. 2006, Pérez-Matus and Shima 2010). Low complexity habitats tend to support fewer prey, whereas high complexity habitats support more (Alvarez-Filip et al. 2011, Carter et al. 2018). There is a trade-off between more, less available prey, and fewer more available.

Predator prey equations have been developed to describe the dynamics of systems in which two species interact as predator and prey, providing a framework to model the dynamics of predator prey systems. The Lotka - Volterra equations were developed separately by Lotka (1925) and Volterra (1926) to predict how the dynamics of interacting predator and prey populations will change over time. The model describes the dynamics of ecological systems that are shaped by interactions between predators and prey (Lotka 1925, Volterra 1926) and predicts that when prey are abundant, predators thrive but will ultimately exhaust their food supply and decline. The prey population increases again as the predator population is low and the populations continue to alternate between cycles of growth and decline.

A large determinant of dynamic stability in a food web is the way a predator responds to a change in prey density, seen in Figure 3.1 as one of three types of functional response (Holling 1959). Habitat complexity and refuge availability can influence the shape of functional response curves and population dynamics. When habitat complexity and therefore refuge availability is high at low prey densities, prey consumption is low because most prey are within refuges. As prey density increases, a 
decreasing proportion are able to take refuge, and predator consumption rates begin to increase, until they level off when predators become satiated, or handling times limit intake rates. As a result, in high complexity habitats, we might expect to see a Type III functional response (Johnson 2006, Toscano and Griffen 2013) (Figure 3.1), which tends to stabilise predator-prey interactions and cycles (Oaten and Murdoch 1975, Sarnelle and Wilson 2008). When habitat complexity and refuge availability is low, prey are easier for predators to capture, even at low density. As their density increases, consumption rates increase more linearly up to the point of satiation in a pattern typical of a Type I or II functional response (Figure 3.1). Type I and type II functional responses can be destabilising because even small densities of prey suffer high levels of consumption. This can ultimately result in less stable population dynamics with large predator-prey oscillations and eventually local prey extinctions (Hassell 1978). Habitats with intermediate complexity, can sometimes be optimal for predator foraging and productivity because they support a higher abundance of prey than low complexity habitats but have fewer refuges for prey to avoid predation than complex habitats (Crowder and Cooper 1982, Rogers et al. 2018).

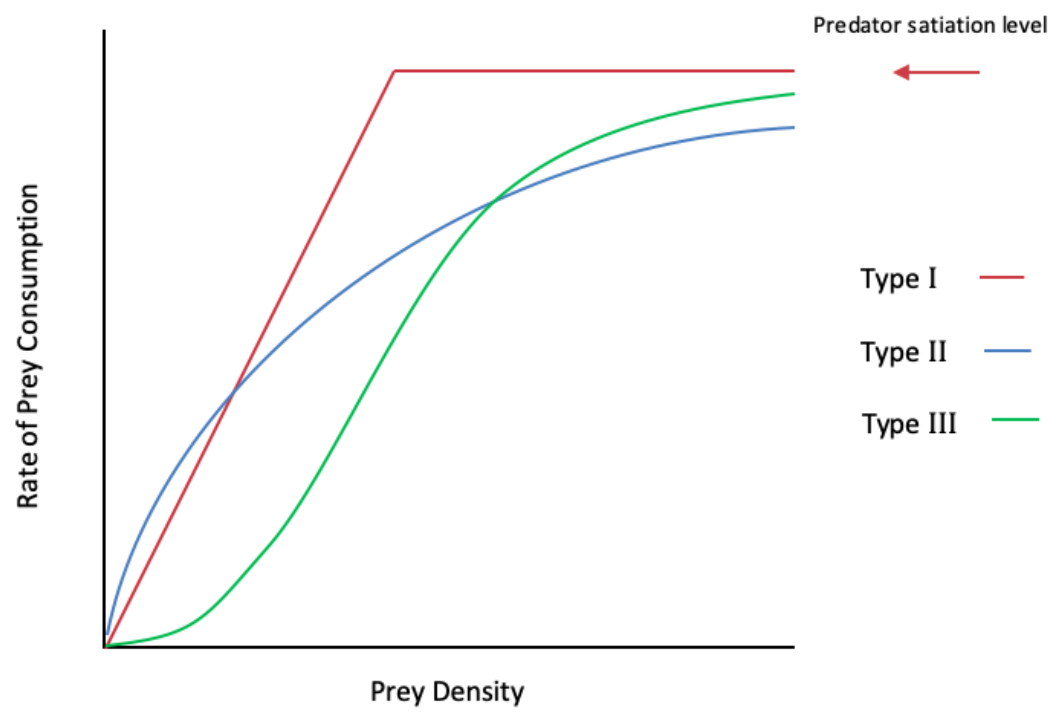

Figure 3.1: Graph showing the relationship between prey consumption and prey density, described by Holling (1959) as three functional response types. 


\section{Chapter Aim}

Macroalgal habitats have potential interacting benefits and costs for predators, as increased macroalgal biomass supports higher richness and diversity of prey species (Pérez-Matus et al. 2007), but prey within these habitats might be more difficult to catch (Wilson et al. 1990). Understanding how macroalgal habitat complexity effects consumption rates in the temperate predator $P$. colias is important in determining whether complex habitat alters their functional response. The aim of this chapter is to evaluate whether macroalgal habitat complexity influences the consumption rates and/or the shape of the functional response curve for the temperate coastal predator blue cod, P. colias, and two of its common prey items.

To determine whether the daily consumption rates of $P$. colias differ in response to habitat complexity, I conducted a mesocosm experiment at Victoria University of Wellington Coastal Ecology Laboratory (VUCEL) between March and October 2019. The experiment manipulated habitat complexity through the use of artificial macroalgal structures based on the giant kelp, M. pyrifera, and explored daily consumption rates across three different prey densities (2,4, and 6). As increased habitat complexity is known to reduce predator consumption rates, I expected the consumption rates of $P$. colias to be higher in the absence of habitat and the functional response of $P$. colias to differ in the absence or presence of artificial macroalgal habitat.

\section{Study Species}

$P$. colias is a large bodied temperate reef fish exclusively found throughout the coastal waters of New Zealand but is most abundant south of the Cook Strait (Carbines, 1998). $P$. colias reside in sub tidal slow flowing habitats such as rocky reef fringes, biogenic structures such as mussel beds and macroalgal forests or gravel and sandy bottoms, often in coastal areas shallower than 150m (Anderson et al. 1998, Carbines and Mckenzie 2004) (Anderson et al. 1998, Carbines and Mckenzie 2004). P. colias is a suitable species to use to investigate the consequences of macroalgal habitat loss on 
the foraging success of a coastal fishery species, as they are a sought after recreational and commercial inshore finfish that often inhabits macroalgal habitats in New Zealand.

Two different prey species were used in the study as $P$. colias is an opportunistic benthic carnivore. The diet of $P$. colias is broad and largely depends on the availability of prey in the local habitat but is dominated by small fish, crustaceans and molluscs (Jiang and Carbines 2002). Therefore a small fish and invertebrate species were selected because they differed in their behaviour and accessibility to blue cod; the common triplefin, Forsterygion lapillum, is a small temperate fish found in subtidal rocky reef habitats around coastal New Zealand and is associated with clusters of mixed algal habitats from Laminareales and Fucales families. The big handed crab, Heterozius rotundifrons, is a small brachyuran crab also abundantly found in rocky coastal habitats around New Zealand, more sedentary in nature than F. lapillum and often found in groups within cobble and rocks.

\subsection{Methods}

\subsubsection{Fish and invertebrate collections}

F. lapillum were collected by hand nets, aided by snorkel and SCUBA, from the infralittoral zone at two Wellington rocky shore sites: Kau Bay (latitude: $-41.287623^{\circ}$, longitude: $174.829033^{\circ}$ ) and Point View Breaker Bay (latitude: $-41.344759^{\circ}$, longitude: $\left.174.820649^{\circ}\right)$. H.rotundifrons were collected by turning over rocks in the intertidal zone of Kau Bay during low tide. Both prey species were collected between February and September 2019. The individuals collected were returned to Victoria University's Coastal Ecology Laboratory (VUCEL) and stored separately prior to all trials in acrylic plastic tank with flowing natural seawater. Tanks measured $59 \times 30 \times 30 \mathrm{~cm}$, and were lined with a layer of cobble ( $2 \mathrm{~cm}$ thick) to provide some natural substrate. Both prey species were fed a diet of crushed mussel every 3 days. Blue cod, P. colias were collected by local fishermen from the Cook Strait, Wellington between March and October 2019 using cod pots (to prevent damage to mouths or lips from line fishing). 
Predators were maintained in an outdoor plastic $1000 \mathrm{~L}$ tank with flow through seawater at VUCEL for 36 hours prior to experiments. Predators were starved for 36 hours prior to each experiment and were not unnecessarily handled in order to reduce stress.

\subsubsection{Predator consumption with and without habitat complexity}

To investigate the effect of habitat complexity on blue cod predation rates, nine experimental mesocosms were constructed from 1000L tanks with constant flow through seawater and shade cloths to standardize light availability. Each trial used a mesocosm that contained a single $P$. colias, one of three densities $(2,4$ or 6$)$ of $F$. lapillum or $\mathrm{H}$. rotundifrons and either a standardized artificial habitat constructed to replicate the refuge provided by a common New Zealand macroalgae, Macrocystis pyrifera, or no habitat at all. The artificial macroalgal habitat (Figure 3.2) replicated 3 stipes $(75 \mathrm{~cm}$ in length) containing 20 alternating blades $1.5 \mathrm{~cm}$ apart, $15 \mathrm{~cm}$ below the surface of the water. The 3 stipes were each made of braided polypropylene rope and the blades were stripes of green and brown polyester bemsilk fabric cut $40 \mathrm{~cm}$ long and $5 \mathrm{~cm}$ wide then tied to the rope. All three ends of the rope had a $40 z$ lead reef sinker attached to keep the artificial habitat weighted to the bottom of the tank floor while the other three ends were tied to a $30 \times 10 \mathrm{~cm}$ plastic float, allowing the artificial habitat to span the entire water column. Each $P$. colias was between $33 \mathrm{~cm}$ and $35 \mathrm{~cm}$ in length which is known to be the length range for mature adults. Both male and female $P$. colias were used as sex was not assumed to have an effect on the outcome of the experiment. Prior to the experiment, $P$. colias were housed individually and starved for 36 hours.

To begin each trial, at 08:00 an opaque plastic barrier was added to the middle of the tank to separate the tank into two sides. A single predator was contained on one side and the prey were haphazardly added to the other side of the partition, which also contained the complex habitat when used. This allowed the prey to acclimate to the tank and if they wanted to, to take refuge in the complex habitat. The partition was 
left in place for 1 hour and then removed so that predators could access prey. The mesocosms were checked after 24 and 48 hours, at which points the remaining prey were counted. After a maximum of 48 hours, trials were ended and any remaining prey were recorded and removed. A trial was stopped early if all prey were consumed before 48 hours.

(a)

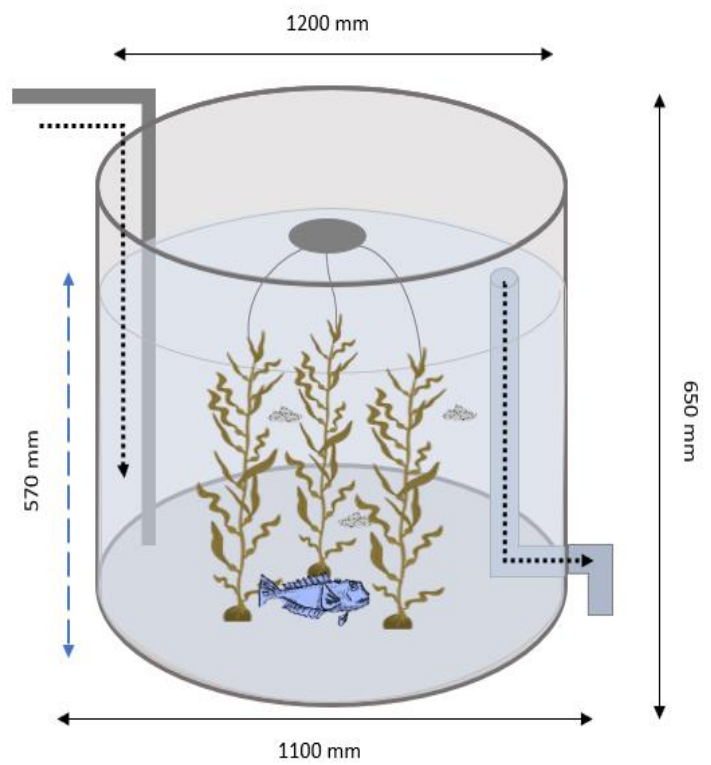

(b)

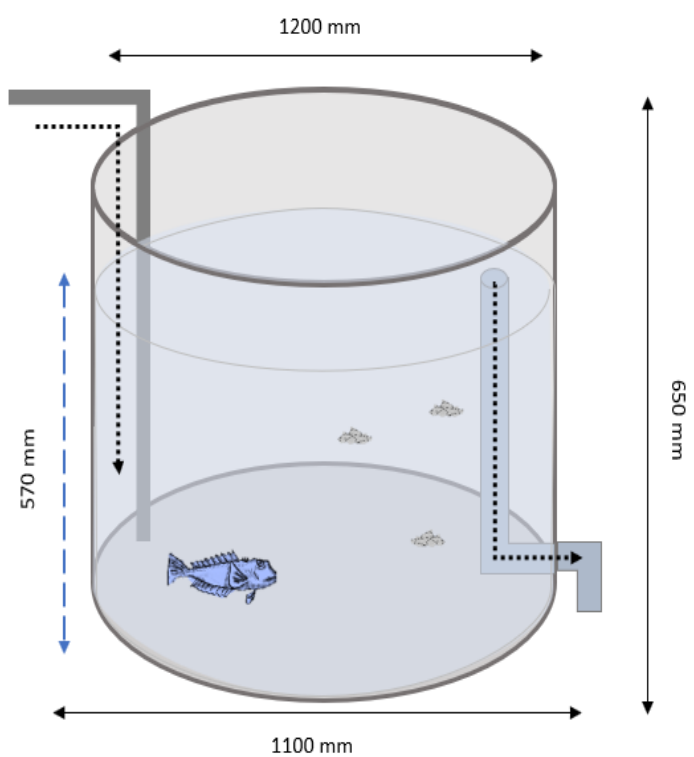

Figure 3.2: Experimental setup of the mesocosms used to evaluate the consumption rate on prey items by the model predator $P$. colias with and without (right) artificial macroalgal habitat. Unbroken arrows represent the dimensions of the tanks, dashed arrows represent the height of the water level and dotted arrows represent the flow of seawater. In trials with artificial macroalgal habitat (left), each tank contained three artificial macroalgal fronds with weights on the bottom ends and the top ends tied to a surface float.

\subsubsection{Statistical Analyses}

Daily consumption rate was calculated by dividing the number of prey consumed by 2 days (the maximum length of the trial), except if all prey were consumed within the first day, in which case the number of prey consumed was divided by 1 day. Generalized linear models (GLM) specifying a Poisson error distribution and a log linear link function were used to compare the daily consumption rates of $F$. lapillum and $H$. rotundifrons with and without macroalgal habitat both separately and also between 
prey species. The initial prey density for each trial was added to the model as an offset, as the daily consumption rate in each trial was relative to the number of prey available per trial (either 2, 4 or 6). Statistical analyses were conducted using the base package in R ( $R$ Core Team 2018).

As the consumption rate of $F$. lapillum by $P$. colias was found to significantly differ with and without macroalgal habitat, functional response curves were fitted to evaluate whether the consumption rates also differed as a function of $F$. lapillum density. Response curves were calculated using non-linear least squares regression $(n / s)$ and fitted to equations of the Holling Type I, II and III functions:

Holling I:

$$
F=a x+b
$$

Holling II:

$$
F=\frac{a x}{1+b x}
$$

Holling III:

$$
F=\frac{(a x)^{n}}{1+(b x)^{n}}
$$

$F$ denotes number of prey consumed, $a$ denotes attack rate of prey, $b$ denotes average time handling prey, $\mathrm{n}$ denotes the exponent that describes the shape of the functional response and $x$ denotes the prey density. Holling curves were compared using Akaike Information Criterion (AIC) values to find the Holling type models of best fit (lower AIC implies a better model fit). The statistical software R (R Core Team 2018) was used, along with the package tidyverse (Wickham et al. 2019) . 


\subsection{Results}

\section{Daily consumption with and without complexity}

The daily consumption rate of $F$. lapillum by $P$. colias was significantly lower with complex habitat, than without, ( $t=0.73$, df $=20, P<.05$, Figure 3.3 ). The mean daily consumption rate was twice as high without habitat $(2.27 \pm 0.57 \mathrm{SE})$ than with habitat $(1.04 \pm 0.27 \mathrm{SE})$. There was no significant difference between the consumption rates of $H$. rotundifrons with or without complex habitat (Figure 3.3). The daily consumption rate without habitat was significantly higher for F. lapillum than for $\mathrm{H}$. rotundifrons, $(t=$ 1.37, $\mathrm{df}=18, P<.01$, Figure 3.3). The mean daily consumption rate of $F$. lapillum without habitat was 4 times higher $(2.27 \pm 0.57 \mathrm{SE})$ than of $H$. rotundifrons $(0.61 \pm 0.33$ $\mathrm{SE})$. There was no significant difference between the consumption rates of $F$. lapillum and $H$. rotundifrons with complex habitat (Figure 3.3).
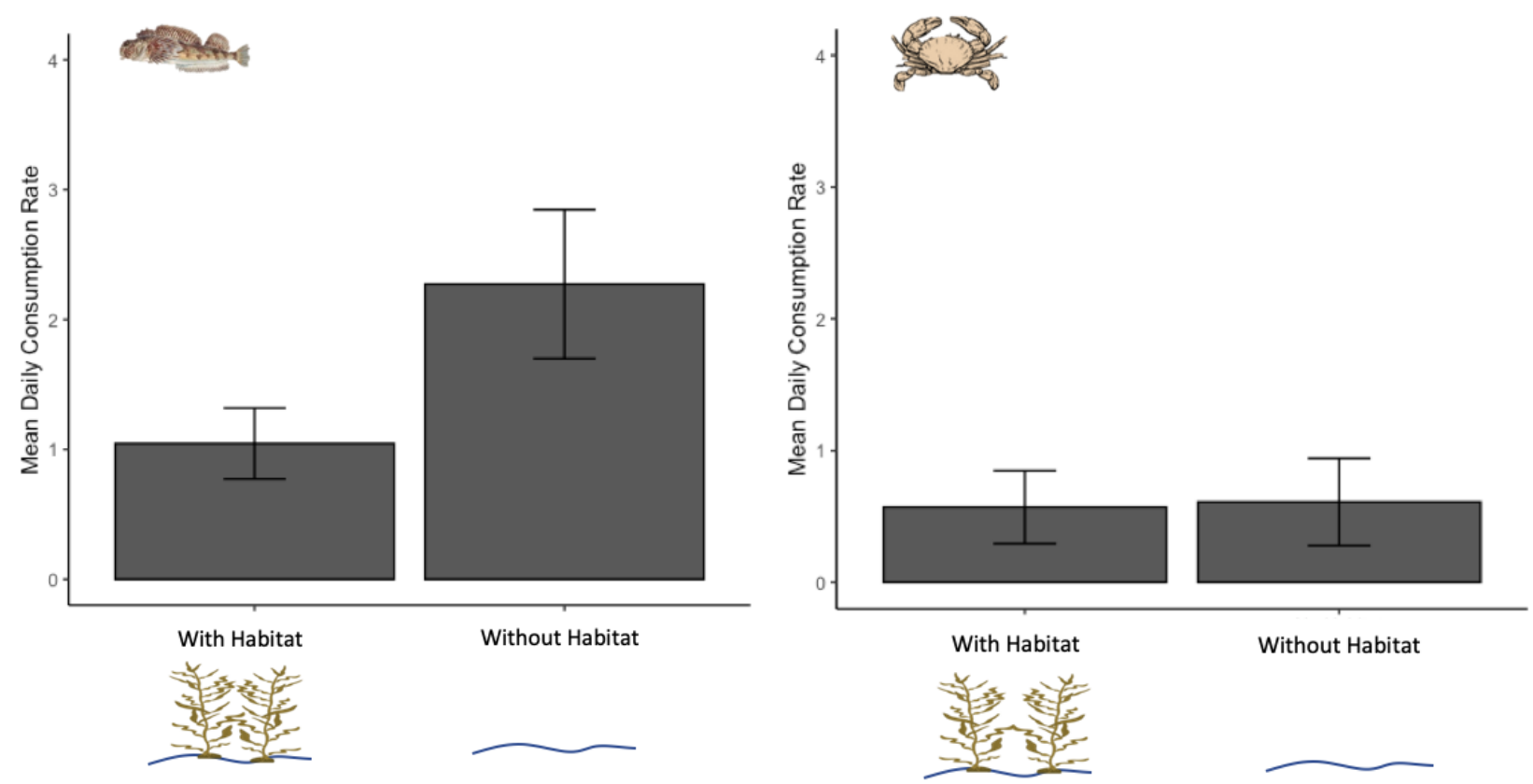

Figure 3.3: Absolute daily consumption rate of $F$. lapillum and $H$. rotundifrons (mean $\pm \mathrm{SE}$ ) by $P$. colias, pooled over the trials with or without artificial macroalgal habitat. 


\section{Functional response with and without complexity}

By considering the number of prey consumed as a function of their density with and without habitat complexity, we explored whether complex habitats alter the functional response curve for $P$. colias for each model prey species. For F. lapillum, there was no significant difference in the model fit between a Type I and Type II functional response with and without habitat complexity (Table 3.1). With the limited amount of data, and the prey density range that we explored, it was not possible to fit a Type III functional response. Since Type $\mathrm{I}$ is the simpler model, it is the model of choice for both treatments (Figure 3.4). It is clear when examining the data, that higher replication, and in particular, data at a much higher prey density is needed to examine the full functional response and to determine whether it differs with and without macroalgal habitats. However, with the range of prey densities used, there is a qualitative difference in the slopes of the Type I (linear function) function with and without habitat complexity (Figure 3.4). The shallow slope observed in the presence of complex habitat could be the start of an accelerating curve indicative of a Type III functional response, whereas the steeper rate of increase without habitat could indicate the beginning of either a Type I or Type II response (Figure 3.5). Further studies should explore this response over a broader range of prey densities as this would inform fisheries models and management for $P$. colias.

Table 3.1: AIC values for models of Type I and II functional responses fitted to F. lapillum consumption with and without habitat complexity.

\begin{tabular}{|l|l|l|}
\hline Habitat Complexity & Model (Functional Response) & AIC \\
\hline \multirow{2}{*}{ With Habitat } & Type I & 37.92 \\
\cline { 2 - 3 } & Type II & 37.87 \\
\hline \multirow{2}{*}{ Without Habitat } & Type I & 40.26 \\
\cline { 2 - 3 } & Type II & 37.95 \\
\hline
\end{tabular}



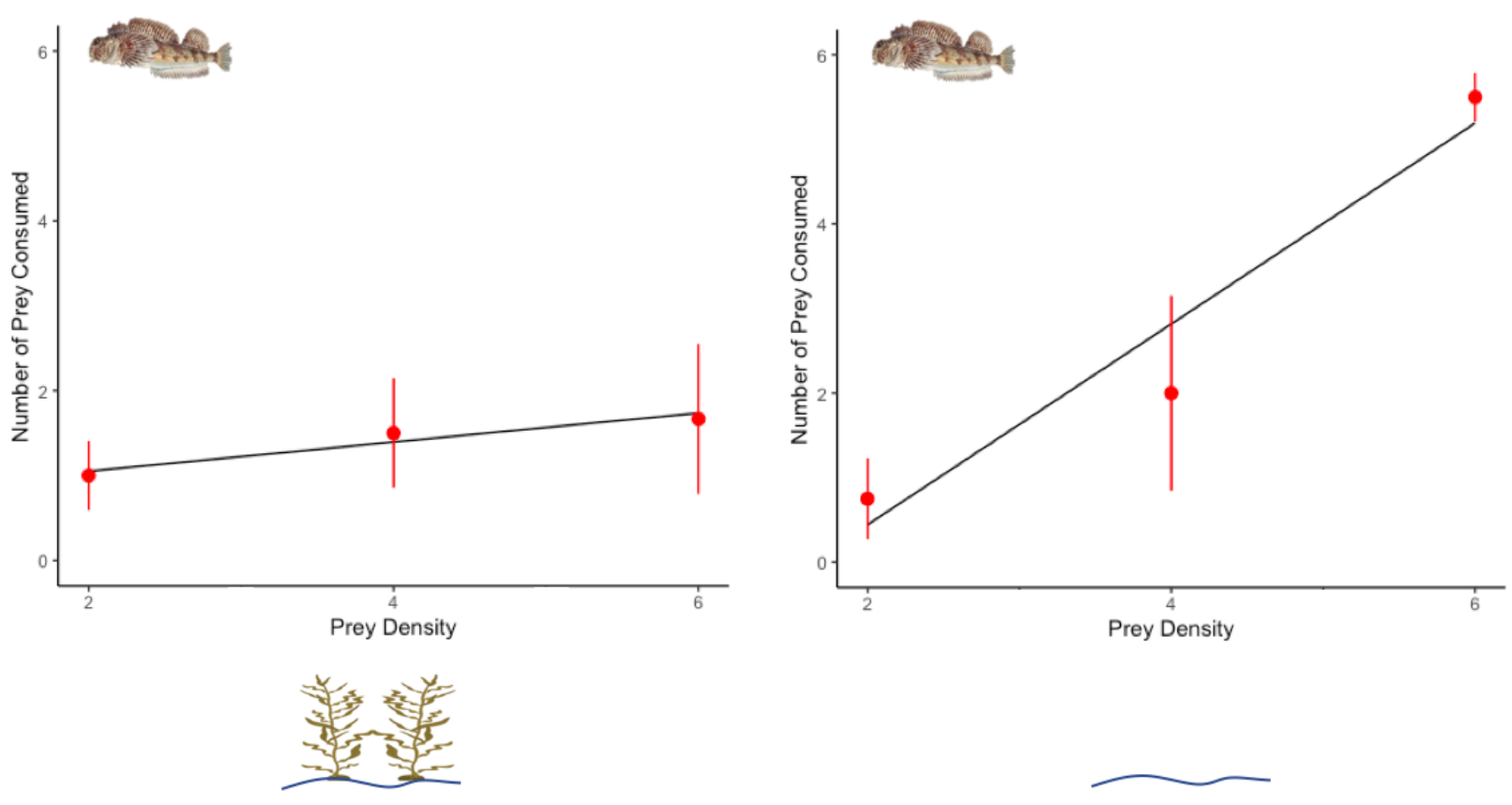

Figure 3.4: Number of $F$. lapillum consumed (mean $\pm \mathrm{SE}$ ) by P.colias at initial densities of 2, 4 or 6 and with artificial macroalgal habitat (left) or without (right). Type I Holling functions (linear function) fitted to the number of $F$. lapillum consumed by $P$. colias, with increasing prey density.

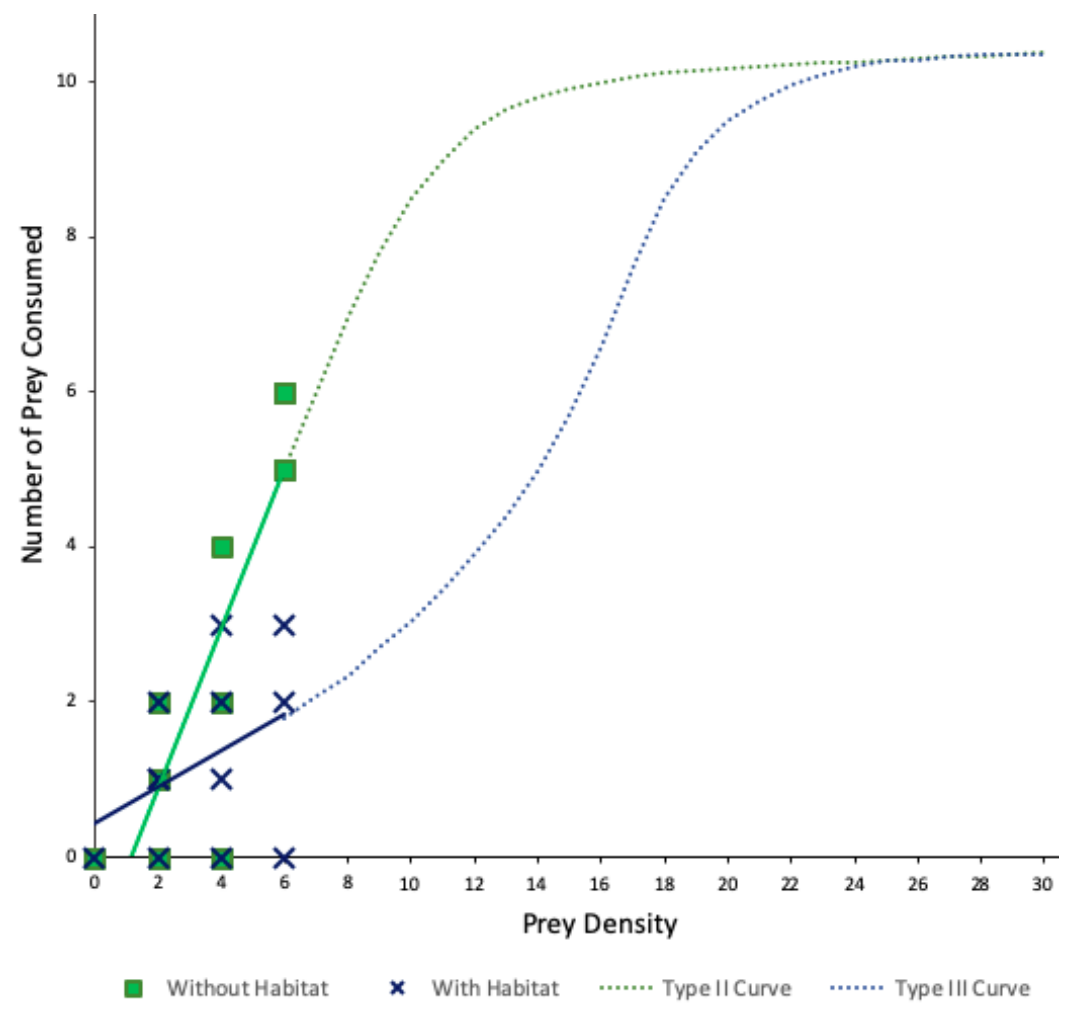

Figure 3.5: Different slopes plotted with increasing prey density and consumption rate of F. lapillum by $P$. colias, with and without macroalgal habitat. The prey densities up until F. lapillum are plotted against true consumption data with linear a equation, after which the dotted lines show the possible extrapolation of the curve if the consumption by $P$. colias with habitat followed a Type III response (sigmoid) and without habitat a Type II response. 
The non-significant effect of complex habitat on the daily consumption rates of $H$. rotundifrons meant that it was unlikely that any difference would be found between functional response curves with and without habitat, and we did not fit curves to this data (Figure 3.6)
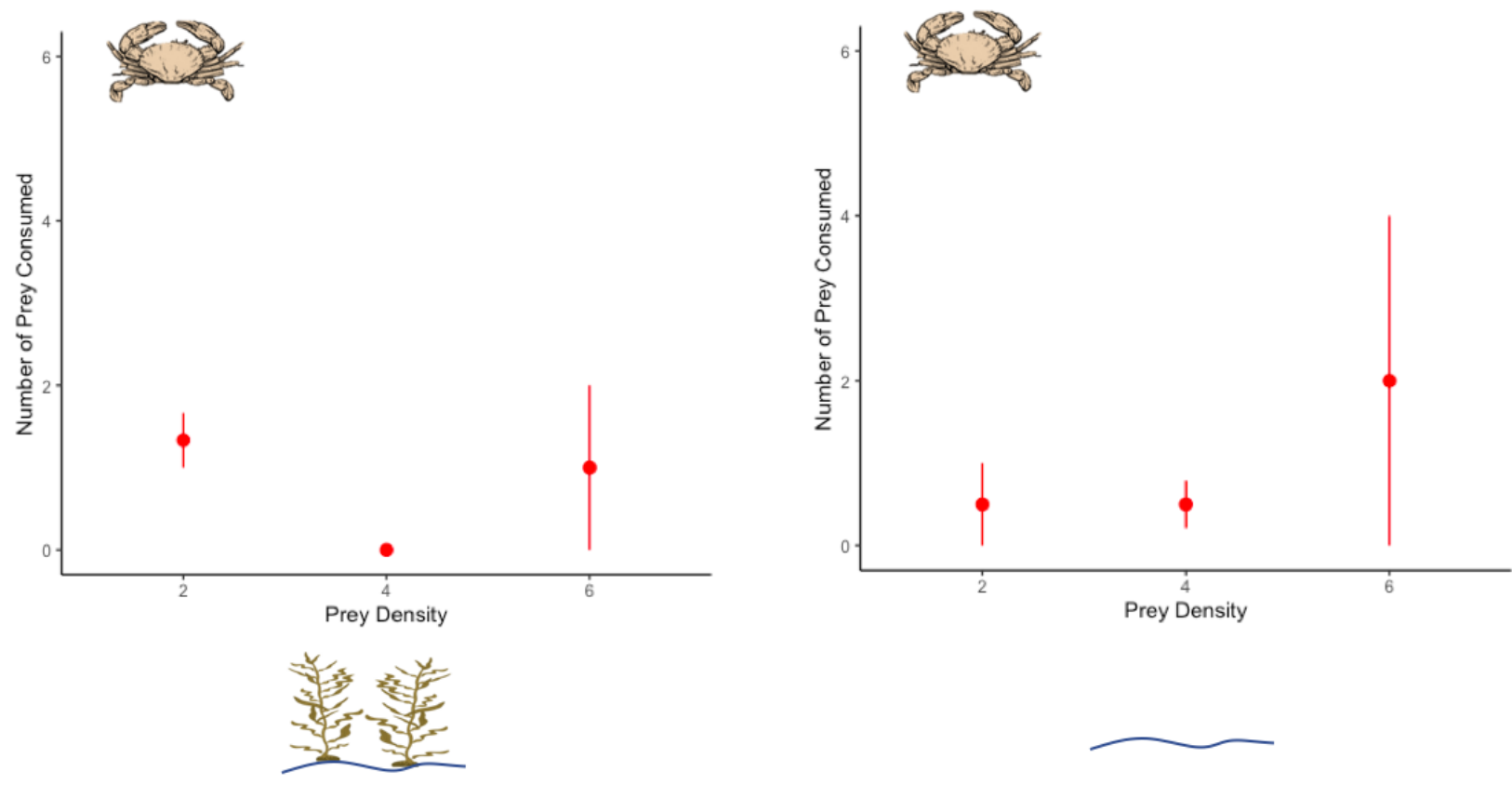

Figure 3.6: Number of $H$. rotundifrons consumed (mean $\pm \mathrm{SE}$ ) by $P$. colias at initial densities of 2, 4 or 6 and with artificial macroalgal habitat (left) or without (right).

\subsection{Discussion}

This study suggests that a loss of macroalgal habitat complexity may result in increased consumption rates of temperate prey fish F. lapillum by $P$. colias. However, a lack of data on consumption rates at high prey density meant that it was not possible to examine differences in the functional response. The consumption of prey is still accelerating with $6 \mathrm{~F}$. lapillum, the highest prey density used in this study, in both responses with and without habitat. Higher prey densities are needed to capture the complete response of $P$. colias, where prey reach densities high enough for handling times and satiation to slow the predators consumption rate to a point where it reaches an asymptote. Given the difference in the slopes of the response curves with and without habitat, the potential accelerating response with increasing density of $F$. 
lapillum with habitat, which is typical of Type 3 functions, could possibly be attributed to the refuge offered by habitat complexity.

These results are consistent with similar studies that found habitat complexity and increased refuges reduce consumption rates when compared to less complex habitats (Murdoch and Oaten 1975, Lannin and Hovel 2011, Clemente et al. 2013). The insignificant difference between the consumption rate of $H$. rotundifrons with and without macroalgal habitat could be due to the lower preference for complex macroalgal habitats under potential predation risk, as was found in the earlier experiment on the influence of habitat complexity on $P$. colias prey availability and behaviour. However the similar consumption rates with and without habitat could also be due to the defensive nature of crabs. Specifically, $H$. rotundifrons have been observed to extend their appendages and become rigid when grasped by a predator, which can physically inhibit predators from consuming prey by increasing the gape size needed for swallowing (Hazlett and McLay 2000). The higher consumption of $F$. lapillum than $H$. rotundifrons without habitat also suggests that the crabs are less palatable or desirable to $P$. colias, possibly due to their defensive behaviour and hard shell.

The cost of habitat complexity on predator consumption rates is also observed in a similar study where increased kelp cover reduced detection and predator attack success of a temperate reef fish at low prey densities (Johnson 2006). Although artificial macroalgal habitats were used in the experiment, they replicated the commonly found macroalgae $M$. pyrifera which has many large long blades. Blades provide a physical barrier for small fish to sit on and cling to, and the increased structural complexity provided by macroalgae comes at the cost of reduced accessibility for large bodied predators (Warfe and Barmuta 2004). Alongside a physical barrier, macroalgae also provide a visual refuge for small individuals which has been found to reduce a predators visual contact with prey (Savino and Stein 1982, Michel and Adams 2009). 
Complex macroalgal habitats may support increased refuge availability and lower prey consumption rates, however with increasing density of prey, there will be more competition for refuges. This may eventually result in an increase in foraging success on remaining prey who have reduced access to refuges (Gotceitas and Colgan 1989). A weaker reduction in prey mortality in complex macroalgal habitats has been attributed to increased prey abundance, when compared to lower prey densities (Johnson 2006), which is something this study could potentially disentangle with higher prey densities. Small prey fish comparable to F. lapillum find complex macroalgal habitats important for refuge and food availability, and this is shown by the reduction of herbivorous and omnivorous fish abundance in habitats with low macroalgal complexity (Parsons et al. 2016). Macroalgal systems support increased abundance and biodiversity (Alvarez-Filip et al. 2011) and increased macroalgal cover is positively linked to increased abundances of small fish (Willis and Anderson 2003). Therefore increased abundance of small prey supported by complex macroalgae may outweigh the trade-off of reduced foraging success of predators in complex habitats. 


\section{Chapter 4}

\section{The consequences of habitat loss for the population dynamics of $P$. colias}

\subsection{Introduction}

Determining a populations' growth rate is important for predicting future trends in abundance and population dynamics (Sibly and Hone 2002). Population growth rates describe the per capita rate of growth and influence whether a population is stable or whether the abundance is changing over time (Caley et al. 1996). Larval supply and recruitment influence population abundance but physical and biological factors can also contribute to variability in recruitment rates (Menge 2000). Varying predation pressure, resource availability and environmental forces drive variability in larval mortality, which influences the strength and patterns of recruitment to the adult population, both spatially and temporally (Cushing 1995, Pécuchet et al. 2015). Resource availability is a key determinant of individual and population growth (Sibly and Hone 2002), and for marine predators, this is largely driven by the availability of prey. Generalist predators opportunistically feed and consume more than one type of prey, often switching between prey species that are more abundant and temporally relieving less abundant prey populations from predation pressure (Nordberg and Schwarzkopf 2019). Prey switching can help to sustain or increase predator growth and abundance by stabilising food availability because prey at low densities suffer reduced attack rates and the more abundant species are targeted (Oaten and Murdoch 1975). Specialist predators have a narrower breadth of diet and although they are typically more efficient at foraging on preferred prey sources, this limits their growth and abundance if they overexploit their prey (Terraube et al. 2011). Prey availability is also influenced by intraspecific and interspecific competition between predators. As predator abundance increases, the ratio between predators and prey increases, reducing predator foraging success (Persson 1983). Habitat complexity supports refuge availability, which limits foraging in predators, further increasing competition for prey (Crowder and Cooper 1982). Mortality influences population growth rates in the form 
of natural mortality, predation, and in some marine species due to fishing. Natural mortality rates can be density dependent, often due to limited refuge availability as well as predator functional responses (Anderson 2001). Additionally, certain populations are subject to mortality by fishing which can affect age-structures and abundance, impacting the growth of populations (Jensen 1984).

Continued ecosystem processes and function depend on habitats maintaining complexity to support local population dynamics (Godbold et al. 2011). Using models that explicitly capture the effects of refuge loss on tropical coral reefs, it has been shown that declining habitat complexity results in as much as a three-fold decrease in fisheries productivity, driven by decreased abundance and growth of large-bodied predators (Rogers et al., 2014). An increase in climate driven threats to macroalgal habitats has also been found to simplify food webs, due to reduced prey availability and decreased diversity and abundance of associated species, causing a trophic cascade through the rest of the food web (Byrnes et al. 2011). Macroalgal habitats have potential interacting benefits and costs for predators. Simplification of rocky reefs into barren habitats can disturb predator-prey relationships by reducing prey abundance (Guidetti 2000, Hesse et al. 2016), but also increasing predator foraging success on the few remaining prey who have reduced access to refuges (Gotceitas and Colgan 1989). In contrast, complex macroalgal habitats are known to support greater prey abundance and biodiversity (Pérez-Matus et al. 2007, Alvarez-Filip et al. 2011), but refuge availability may invoke a trade-off whereby refuges make prey more difficult to catch, and so less available to predators (Wilson et al. 1990, Wen et al. 2013). Using experimental manipulation to assess predation success, and field observations of prey abundance with and without habitat complexity in isolation, make it difficult to evaluate the relative importance of habitat complexity for population dynamics. Population models are a useful tool to integrate empirical data to explore population dynamics. Modelling is particularly valuable when there is a trade-off of variables that require simultaneous examination of their influences on predator-prey systems (Kellner et al. 2010). Results from such models can highlight 
the role of different mechanisms on population dynamics, which would otherwise be unclear from observed trends found experimentally or in the field.

In Chapter 3, we showed that complex habitats reduce consumption rates of Forsterygion lapillum by Parapercis colias. P. colias is an important fisheries species in New Zealand, whose dynamics are driven by a combination of fishing mortality, natural mortality and habitat quality. It is important to understand whether a decline in the complexity of macroalgal habitats known to support $P$. colias (Schiel 1990, Ministry for Primary Industries 2017), will impact their population dynamics. Using a simple population model, the aim of this chapter is to explore the trade-off between prey abundance and predation success on the population dynamics of $P$. colias with and without macroalgal habitat complexity.

\subsection{Methods}

\subsubsection{General model of population dynamics}

Initially, a general theoretical population model, based on ordinary differential equations, was developed to simultaneously examine the influence of prey availability and predator foraging success on the dynamics of a predator-prey system. The general model was then implemented for a temperate system, with and without macroalgal habitat complexity, to capture the trade-off between $P$. colias prey abundance and predation success. As $P$. colias is a generalist consumer that opportunistically targets a broad range of prey (Jiang and Carbines 2002), the predator-prey system described by the general model incorporates a predator with multiple prey (Figure 4.1). The population dynamics of the predator $P$. colias are examined as they relate to the availability and attack rate of a focal prey species F. lapillum, a small temperate fish, and an alternate prey source, modelled as a more sedentary invertebrate. 


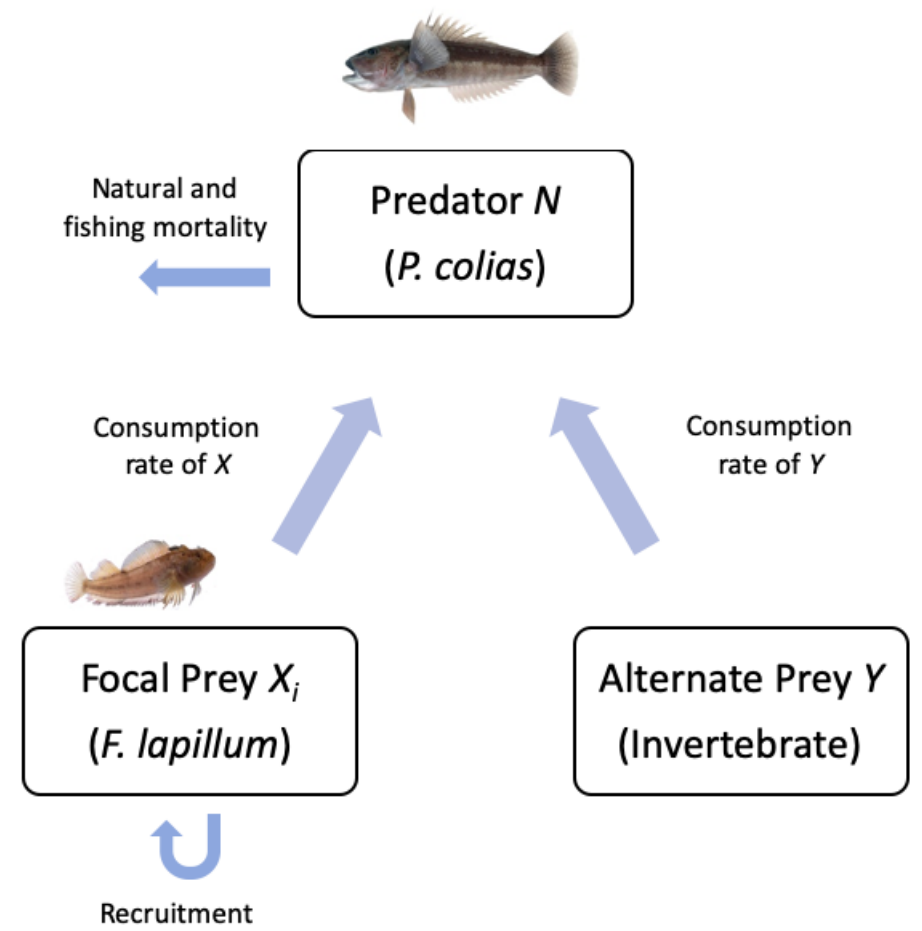

Figure 4.1: General model schematic with arrows indicating the factors considered and examining the trade-off between the availability and predation of multiple prey for predator population dynamics.

To explore changes in the abundance and growth $P$. colias populations, the predator-prey system can be represented by the following equations:

focal prey (F. lapillum),

$$
\frac{d X_{i}}{d t}=r_{i}\left(1-X_{i} / K_{i}\right) X_{i}-a_{i} N X_{i}
$$

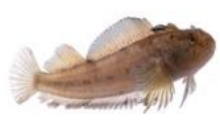

Predator (P. colias),

$$
\frac{d N}{d t}=\left[c\left(a_{Y} Y+\sum a_{i} X_{i}\right)-d_{N}\right]-h_{N} N
$$

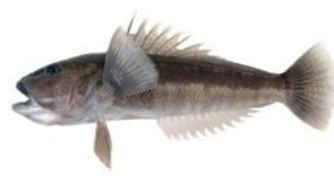

(2)

Equation (1) describes the dynamics of the focal prey, F. lapillum (X). The focal prey population dynamics are driven by the intrinsic rate of increase, $r$ and the carrying capacity $K$ for i number of focal prey $X$. The second term is loss to predation described by the attack rate $a$ of the predator, $P$. colias $(N)$. 
In order to capture the broad diet of $P$. colias, a constant pool of alternate prey $Y$ is included in the model. We assume that $Y$ represent a suite of prey species whose densities would be similar with and without macroalgae, due to them not explicitly using macroalgae as a refuge or microhabitat.

Equation (2) describes the dynamics of our $P$. colias predator $(N)$. The predator's population dynamics are driven by its population growth rate, minus natural mortality $d_{N}$ and mortality due to fishing $h_{N}$. Population growth rate is a function of the conversion efficiency of consumed prey (focal $X$ and alternate $Y$ prey) into additional predators $c$, and the attack rate of the predator on its focal prey $a$, and its alternate prey $a_{y}$.

Parameters for the base model were taken from previous studies wherever possible, otherwise biologically realistic values were derived. The population growth of the focal prey, F. lapillum is driven by its annual intrinsic rate of increase, $r$ and remains constant in all models. The annual natural mortality rate of $P$. colias, $d_{N}$ and the conversion efficiency of consumed prey into additional predators, $c$ is also assumed to be constant in all model runs. Model parameters and sources are detailed in Table 4.1.

\subsubsection{The influence of habitat complexity}

Using the general model, two contrasting simulations were developed to describe the key population dynamics of $P$. colias in systems with or without macroalgal habitat, to examine the trade-off between predation and prey availability. To model these contrasting systems, estimates of attack rates on the focal prey F. lapillum and an alternate prey were taken from the results of mesocosm experiments described in Chapter 3, while relative estimates of prey abundance came from existing survey data. $F$. lapillum was used as the focal prey of $P$. colias because it appears to utilise macroalgal habitats for refuge and is consumed at a higher rate when macroalgal habitat is absent (result described in Chapter 3). For the alternate prey, $Y$ attack rates were constant with and without habitat complexity, and were informed by the average consumption rate of $H$. rotundifrons across mesocosm experiments with and without 
habitat (Chapter 3). The underlying assumption is that $H$. rotundifrons is an example of species that does not explicitly using macroalgae as a refuge.

Densities of F. lapillum recorded in experimental transects containing sand and rock as well as transects containing two stands of M. pyrifera (Pérez-Matus and Shima 2010) informed contrasting carrying capacities of $F$. lapillum for scenarios with and without habitat complexity. Alternate prey densities were constant across model scenarios but in the absence of survey data for $H$. rotundifrons, densities of small mobile crustaceans surveyed within a mixed species macroalgal habitat (Atalah and Sneddon 2016), informed the relative abundance of alternate prey in comparison to that of $F$. lapillum. All other model parameters were held constant across complexity scenarios, as detailed in Table 4.1.

To explore the trade-off between prey abundance and consumption rate with and without habitat complexity we examined the difference in population growth rates and equilibrium population density of $P$. colias in the two model scenarios. Models were run for 50 years, with no fishing mortality. Annual population growth rates (3) were calculated as the difference in initial density (at $t=0$ ) and equilibrium density (maximum density), over the time it takes for the population to reach equilibrium density:

$$
\frac{d N}{d t}=\frac{(\text { Equilibrium Density }- \text { Density at } t=0)}{t_{\max \text { density }}}
$$


Table 4.1: List of parameters used in models of population dynamics of $P$. colias, with and without macroalgal habitat.

\begin{tabular}{|c|c|c|c|c|}
\hline Parameter & Estimates & Units & Description & Reference \\
\hline$K_{x}$ & $\begin{array}{l}30 \text { (With Habitat) } \\
20 \text { (Without Habitat) }\end{array}$ & Indv. $/ 30 \mathrm{~m}^{2}$ & $\begin{array}{l}\text { Carrying capacity of } \\
\text { F. lapillum }\end{array}$ & $\begin{array}{l}\text { Estimates based on observations of the } \\
\text { density of F. lapillum in transects either } \\
\text { with } M \text {. pyrifera }\left(1.05 / \mathrm{m}^{2}\right) \text { or bare sand } \\
\left(0.65 / 4 \mathrm{~m}^{2}\right) \text { (Pérez-Matus and Shima 2010). }\end{array}$ \\
\hline$Y$ & 15 & Indv. $/ 30 \mathrm{~m}^{2}$ & $\begin{array}{l}\text { Density of an } \\
\text { alternate prey source }\end{array}$ & $\begin{array}{l}\text { Estimate based on observations of mobile } \\
\text { crustacean density within a mixed species } \\
\text { macroalgal assemblage }\left(0.4 / \mathrm{m}^{2}\right) \text { (Atalah } \\
\text { and Sneddon 2016). }\end{array}$ \\
\hline$a_{x}$ & $\begin{array}{l}1.04 \text { (With Habitat) } \\
2.27 \text { (Without Habitat) }\end{array}$ & Prey/P. colias & $\begin{array}{l}\text { Attack rate of Focal } \\
\text { Prey }\end{array}$ & $\begin{array}{l}P \text {. colias consumption rates of F. lapillum } \\
\text { with and without habitat (Chapter } 3 \text { ). }\end{array}$ \\
\hline$a_{Y}$ & 0.59 & Prey/P. colias & $\begin{array}{l}\text { Attack rate of } \\
\text { Alternate Prey }\end{array}$ & $\begin{array}{l}\text { P. colias consumption rate of } H \text {. } \\
\text { rotundifrons averaged over mesocosms } \\
\text { with and without habitat (Chapter } 3 \text { ). }\end{array}$ \\
\hline$d_{N}$ & 0.49 & /year & $\begin{array}{l}P \text {. colias natural } \\
\text { mortality rate }\end{array}$ & $\begin{array}{l}\text { FishBase (M). Accessed 16/12/19 at } \\
\text { http://www.fishbase.org }\end{array}$ \\
\hline$c$ & 0.03 & P. colias/prey & $\begin{array}{l}\text { Predator conversion } \\
\text { efficiency }\end{array}$ & $\begin{array}{l}0.06 \text { (Spencer and Collie 1996) } \\
0.01 \text { (Baskett 2006) } \\
\text { Value unknown for P. colias so was chosen } \\
\text { to fall within the realm of values from } \\
\text { similar models. }\end{array}$ \\
\hline$r_{x}$ & 7.82 & /year & $\begin{array}{l}\text { F. lapillum intrinsic } \\
\text { rate of increase }\end{array}$ & $\begin{array}{l}\text { FishBase }\left(r_{m}\right) \text {. Accessed 16/12/19 at } \\
\text { http://www.fishbase.org }\end{array}$ \\
\hline$h_{N}$ & $\begin{array}{l}\text { Explored range }(0,0.1 \text {, } \\
0.2,0.3,0.4,0.5)\end{array}$ & /year & $\begin{array}{l}P . \text { colias fishing } \\
\text { mortality rate }\end{array}$ & Beentjes and Fenwick 2019 ( 0.34) \\
\hline
\end{tabular}




\subsubsection{The impact of fishing mortality}

P. colias is an important NZ fisheries species, whose annual catch is approximately 2150 tonnes (Fisheries New Zealand 2018). Here, we explored the interacting effects of fishing and habitat complexity on the population density of $P$. colias. The effect of fishing was evaluated by including fishing mortality across a range of intensities from 0 to 0.5 . This range captures the current estimate of fishing mortality for $P$. colias ( $F$ 0.34, Beentjes and Fenwick 2019). All other model parameters were held constant (Table 4.1).

\subsubsection{Model sensitivities to prey availability}

Survey data for the densities of $F$. lapillum and an alternate $P$. colias prey source were not available at the same sites with and without macroalgal habitat for this study, and as such, the values used in our models are necessarily estimates, with a high degree of uncertainty. To explore the sensitivity of model results to these uncertain parameters we ran model simulations across a broad range of values for both prey types. The range in both cases included the original parameter value used and at least a halving and doubling of that value in each case. All other parameters were held constant, and $P$. colias equilibrium density was explored as an output.

\subsection{Results}

\subsubsection{The influence of habitat complexity}

The simulated population dynamics indicated that the equilibrium density of $P$. colias after 50 years is twice as high with habitat (5.7 individuals) than without (2.8 individuals) (Figure 4.2). Despite the lower attack rate on F. lapillum, complexity of macroalgal habitats allow prey to reach a density twice as high (7.2 individuals) as in the model without habitat (3.3 individuals). This in turn supports the higher abundance of $P$. colias (Figure 4.2). The population growth rate of $P$. colias with habitat $(0.26$ per year) was also 2 times greater than without habitat (0.11 per year). 

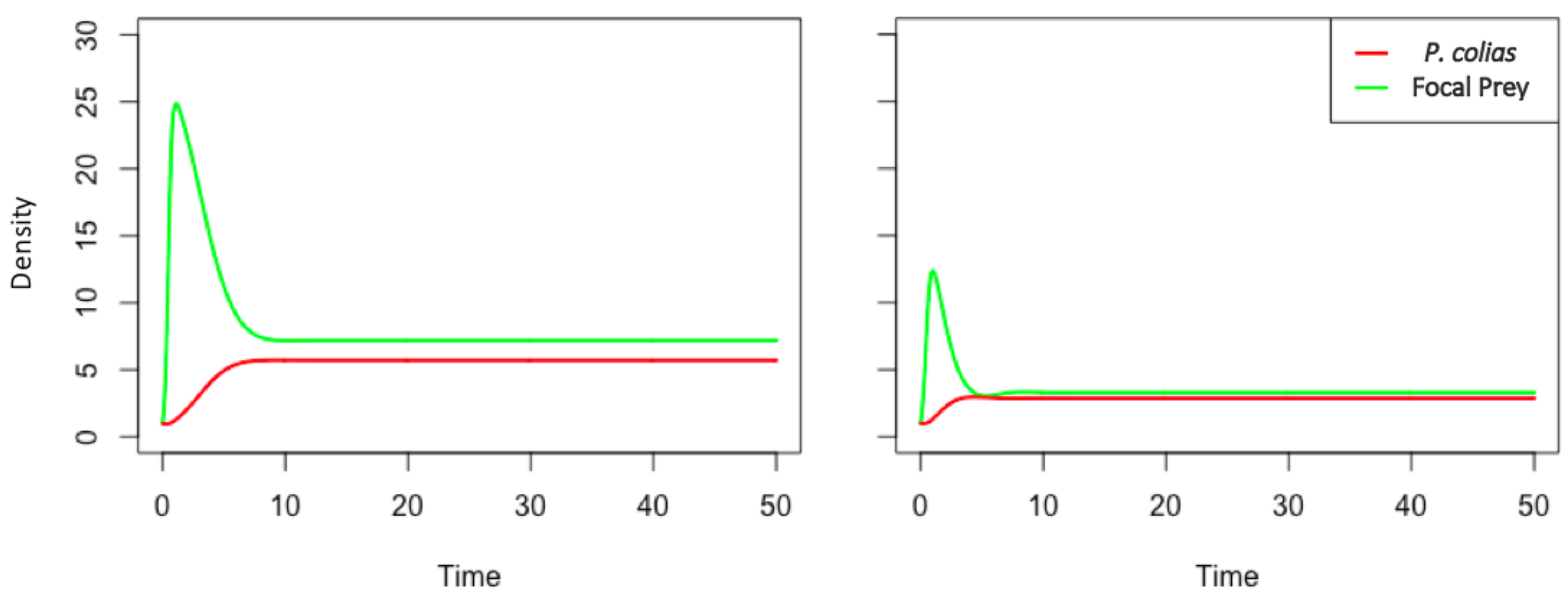

Figure 4.2: Modelled density of predator $P$. colias and focal prey $F$. lapillum over time, with and without macroalgal habitat. Parameter values that are the same in both models: $r_{x}$ (focal prey's per capita growth rate) $=7.82, c$ (conversion efficiency of predator) $=0.03, d_{N}$ (predator's per capita mortality rate) $=0.49, a_{Y}$ (attack rate of other prey) $=0.59, Y$ (density of other prey) $=15$. Parameters that differ between models, with habitat; $K_{X}$ (carrying capacity of focal prey) $=30, a_{X}$ (attack rate of focal prey) = 1.04 , and without habitat; $K_{X}$ (carrying capacity of focal prey) $=20, a_{X}$ (attack rate of focal prey) $=2.27$. In both models, initial densities are set to $X_{0}$ (focal prey) $=1$ and $N_{0}$ (predator) $=1$.

\subsubsection{The impact of fishing mortality}

The equilibrium density of $P$. colias was always higher with habitat complexity than without, under the full range of fishing intensities (Figure 4.3). However, equilibrium density decreases 3 times faster with habitat $(-8.03)$ than without habitat $(-2.52)$ indicating that populations in complex habitats respond more strongly to fishing mortality (Figure 4.3). With increasing fishing pressure, the population growth rate decreases 3 times faster with complex habitat $(-0.50)$ than without $(-0.17)$ (Figure 4.4). Increasing fishing pressure decreases the population proportionally more when there is habitat complexity, with 0.71 of the maximum density of $P$. colias removed with habitat, compared to 0.43 without habitat (Figure 4.5). This indicates that with increasing fishing pressure, the greater decrease in the population growth rate with complex habitat limits the surplus to fish without reducing the population, more than a population without habitat. Notably, the equilibrium density of $P$. colias with (1.69) and without habitat (1.61) was almost the same at the maximum fishing mortality (Figure 4.3). 


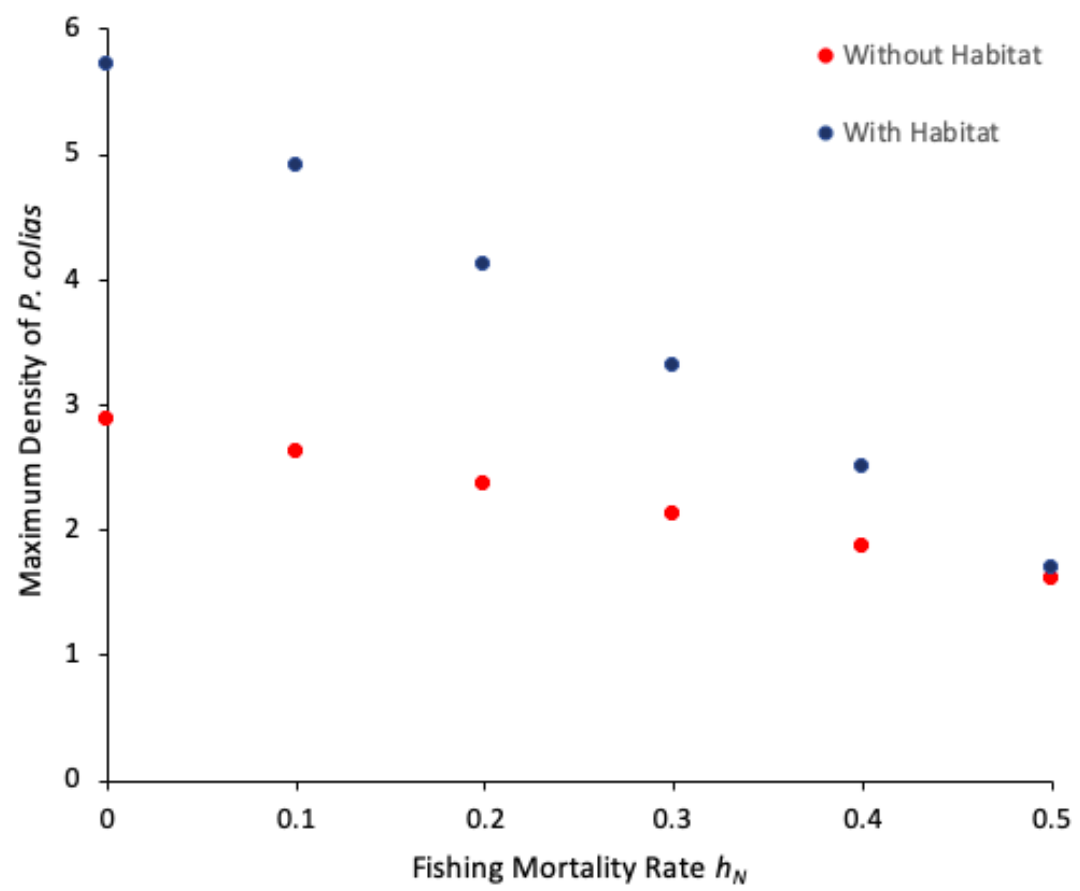

Figure 4.3: Equilibrium density of $P$. colias Parameter values that are the same in both models: $r_{x}$ (focal prey's per capita growth rate) $=7.82, c$ (conversion efficiency of predator) $=0.03, d_{N}$ (predator's per capita mortality rate) $=0.49, a_{Y}$ (attack rate of other prey) $=0.59, Y$ (density of other prey) $=15$.

Parameters that differ between models, with habitat; $K_{X}$ (carrying capacity of focal prey) $=30, a_{X}$ (attack rate of focal prey) $=1.04$, and without habitat; $K_{x}$ (carrying capacity of focal prey) $=20, a_{x}$ (attack rate of focal prey) $=2.27$. In both models, initial densities are set to $X_{0}$ (focal prey) $=1$ and $N_{0}$ (predator) $=1$.

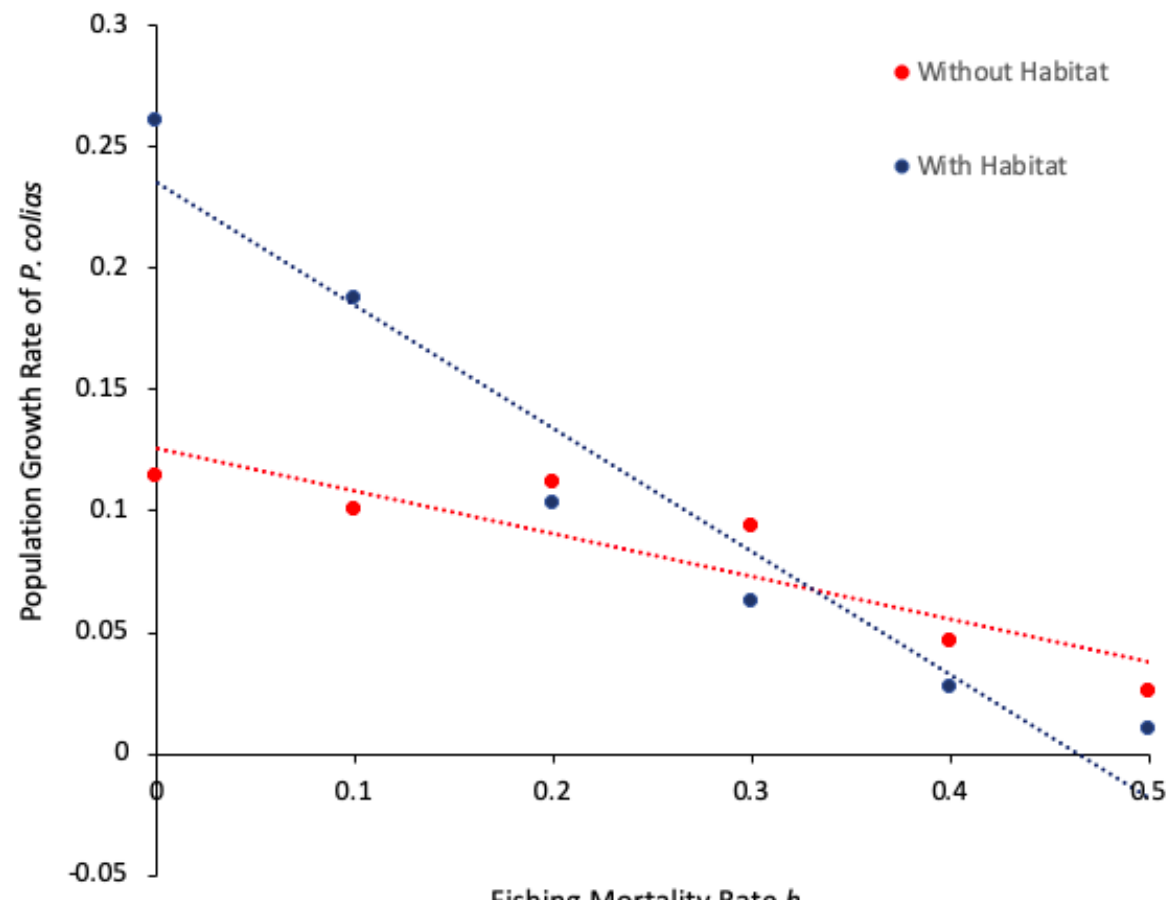

Fishing Mortality Rate $h_{N}$

Figure 4.4: Population growth rate of $P$. colias under varied fishing mortality rates $h_{N}=(0,0.1,0.2,0.3$, $0.4,0.5)$, with and without macroalgal habitat. 


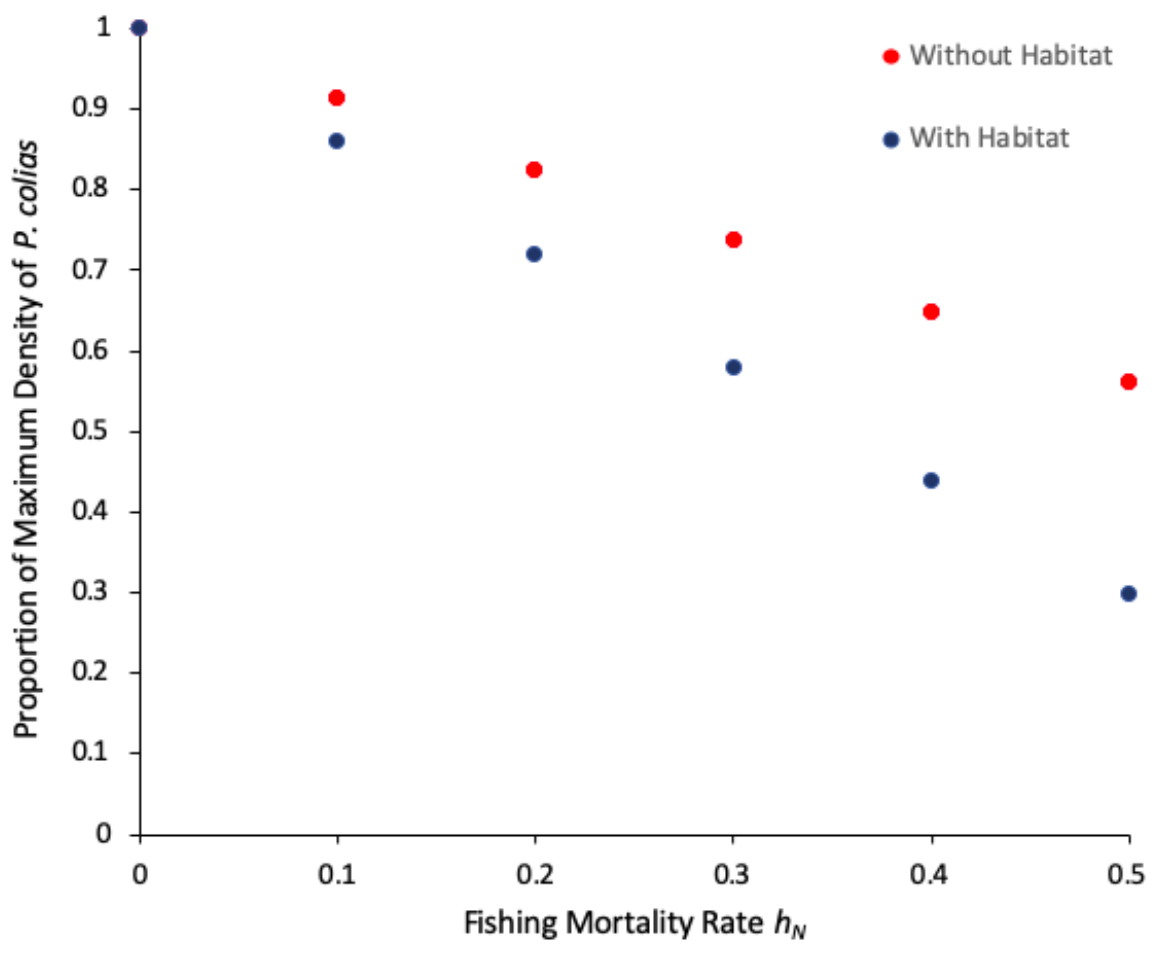

Figure 4.5: Proportion of maximum density of $P$. colias (density without fishing pressure) under varied fishing mortality rates $h_{N}=(0,0.1,0.2,0.3,0.4,0.5)$, with and without macroalgal habitat.

\subsubsection{Model sensitivities to prey availability}

Macroalgal habitats generally support more predators (Figure 4.2), however further exploration of the model sensitivities to varied focal prey carrying capacities and alternate prey densities reveal that increased complexity drives overall more extreme dynamics when (Figure 4.6). P. colias have a maximum abundance of 17 individuals with complex habitat, whereas $P$.colias only reaches a maximum of 6 individuals without habitat (Figure 4.6). With complex habitat, this occurs when the carrying capacity of focal prey is at an intermediate level (Figure 4.6) and P. colias is no longer prey limited by refuges. Without habitat, $P$. colias are most abundant when focal prey have a low carrying capacity (Figure 4.6), due to a higher attack rate on focal prey in the absence of refuge. However the low carrying capacity of the focal prey limits the population from growing as high as it would in complex habitat (Figure 4.6). As the carrying capacity of focal prey increases, the density of $P$. colias decreases as focal prey become overexploited in the absence of refuge (Figure 4.6). 
In both cases, $P$. colias is most abundant when alternate prey are available at an intermediate density (Figure 4.6). P. colias are prey limited and do not persist in both scenarios when the alternate prey density and focal prey carrying capacity is low (Figure 4.6). With complex habitats, when alternate prey density is extremely high and focal prey carrying capacity is low (Figure 4.6), P. colias overexploit the alternate prey and access to the focal prey is limited, resulting in low predator density. However as focal prey become more available in complex habitats, $P$. colias density slightly increases. Without habitat, when alternate prey density is extremely high and focal prey carrying capacity is low (Figure 4.6), P. colias overexploit both the alternate prey and the focal prey (Figure 4.6). As the focal prey become more available without habitat, $P$. colias density also slightly increases (Figure 4.6).

With Habitat

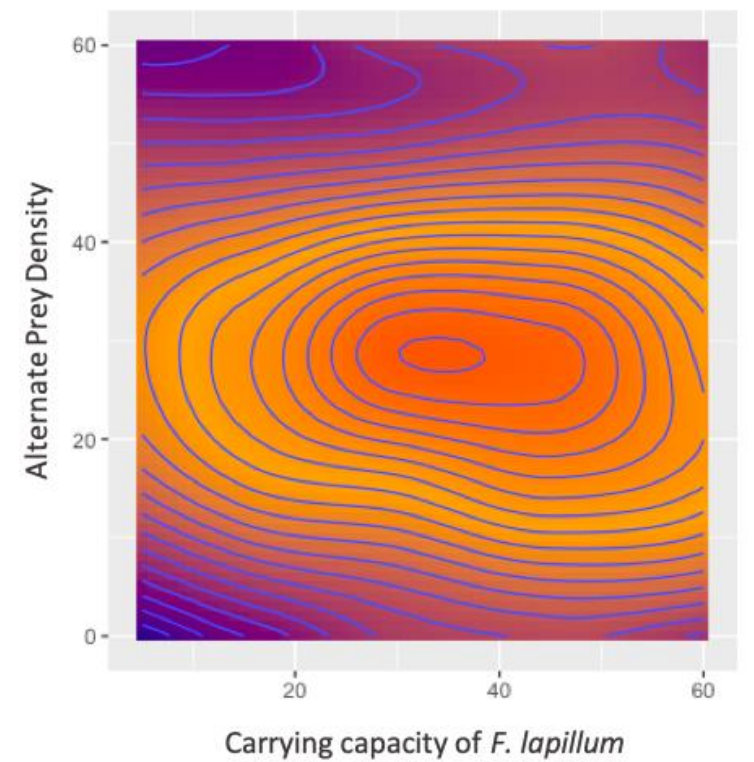

Without Habitat

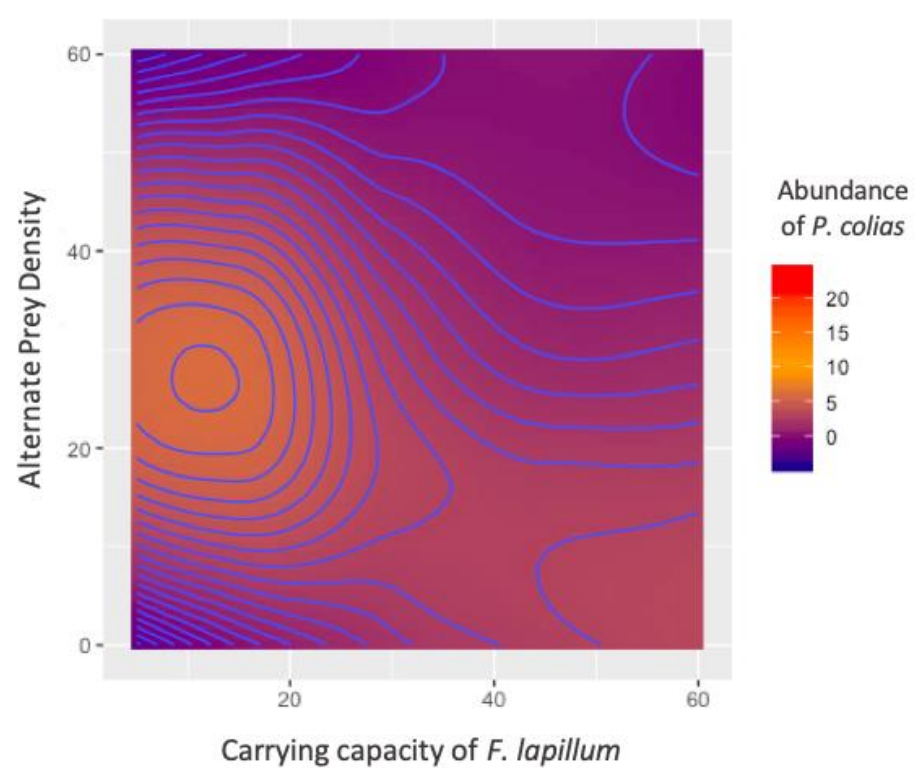

Figure 4.6: Analysis of $P$. colias abundance with and without macroalgal habitat to explore model sensitivities to least certain parameters of prey availability. Focal prey carrying capacities and alternate prey densities range from $0-60$ individuals per $30 \mathrm{~m}^{2}$. 


\subsection{Discussion}

Macroalgal habitats support more predators, but only if there are sufficient alternate and focal prey available. Despite a lower attack rate of $F$. lapillum by $P$. colias, habitat complexity has the trade-off supporting a higher carrying capacity for $F$. lapillum (Pérez-Matus and Shima 2010), allowing the focal prey population to grow to higher densities than in less complex habitat, which in turn supports a higher equilibrium prey density. The increased prey density overwhelms the negative effect of lower attack rates within complex habitat and leads to a greater population growth rate and abundance of $P$. colias. At low focal prey densities, habitat complexity can provide refuge space for most focal prey. At higher densities of focal prey, competition for refuge space increases (Forrester and Steele 2004) and more prey become available to P. colias. Whereas without habitat, the focal prey population may still grow more abundant than the predator initially, but the higher attack rate limits the prey population from reaching as high a density, in turn limiting the population growth of $P$. colias, which drives a lower equilibrium density than in complex habitats.

Fishing pressure appears to have a greater impact on the equilibrium density of $P$. colias in the presence of habitat complexity. Although density of $P$. colias is doubled with habitat complexity without fishing pressure, at high fishing pressure, the density of $P$. colias is effectively equal to the density without habitat. With increasing fishing pressure, there is a greater decrease in the population growth rate with complex habitat, which limits the recovery of $P$. colias. Increased fishing intensity also reduces the surplus to fish, without reducing the population, more than without habitat complexity. The lower decrease in the population growth rate without habitat complexity, is possibly due to the high prey mortality and in turn low prey availability already acting on the predators growth rate and limiting the population abundance. Whereas the population growth rate of $P$. colias with habitat complexity is less affected by prey availability due to increased prey abundance with complex habitats, and the introduction of fishing mortality is more prominent. This suggests that reducing fishing yield is potentially more effective in increasing or sustaining the abundance of $P$. colias than maintaining habitat complexity, as fishing mortality has 
less of an impact without habitat complexity. This is a similar result to Kellner (2010), where increased fishing pressure on their main predator had a greater impact on the reduction in density of Parrotfish when they were relieved of predation pressure, and grew more abundant without fishing pressure, compared to a population that was exposed to increased predation and was already at a lower density initially without the fishing pressure.

The difference in availability of $F$. lapillum due to refuges, coupled with the availability of an alternate prey source, drives extreme dynamics for $P$. colias when compared to lower but more consistent levels of abundance without habitat. Refuges limit the availability of the focal prey for $P$. colias with habitat complexity, however they are more abundant when the carrying capacity of the focal prey increases. However, this is only true when sufficiently high alternate prey are available. When alternate prey are extremely high and focal prey carrying capacity is low, $P$. colias overexploit the alternate prey and access to the focal prey is limited. they also overexploit both prey species when alternate prey density and focal prey carrying capacity are both low. The extreme dynamics are likely due to a low attack rate of $F$. lapillum within macroalgae, which has a knock on effect of a lower predator growth rate when prey are less available at low densities, similar to a refuge effect observed on coral reefs (Rogers et al. 2018). Predators thrive once alternate prey density increases in macroalgal habitats, up until a point, suggesting additional prey support predator persistence and enhance dynamic stability when focal prey availability is limited by refuges (Samanta et al. 2016).

In contrast, the higher attack rate of $F$. lapillum without habitat complexity drives $P$. colias to deplete the focal prey too fast, which limits the prey population from reaching as high a density as it would within complex habitat (Crowder and Cooper 1982), preventing $P$. colias from reaching an equally high abundance. Without habitat, $P$. colias are most abundant when focal prey have a low carrying capacity, due to a higher attack rate on focal prey in the absence of refuge. However the low carrying 
capacity of the focal prey limits the population from growing as high as it would in complex habitat and as the carrying capacity of focal prey increases, the focal prey become overexploited in the absence of refuge.

The abundance of $P$. colias only peaks at low focal prey if an alternate prey source is moderately abundant. If alternate prey are scarce without habitat complexity, the model suggest that $P$. colias abundance is generally low due to a high attack rate on focal prey, which reduces individual prey availability. The higher attack rate on focal prey without habitat results in a less abundant but generally more persistent population of $P$. colias across varying densities of prey. However, it can promote dynamic instability by depleting prey populations at low prey densities and affecting the abundance and possibly the fecundity of predators (Barbraud et al. 2018). As $P$. colias is a generalist predator (Jiang and Carbines 2002), the model shows that even at low focal prey availability, if alternate prey populations increase to a sufficient density to supplement their diet, predators can persist or even grow more abundant (Murdoch 1969). Therefore prey switching is important for dynamic stability when habitat is absent and an alternate prey source is the more abundant population, as generalist predators like $P$. colias will switch to the alternate prey population in order to persist and can relieve their primary prey until it is the more abundant population (Nordberg and Schwarzkopf 2019).

Regardless of whether there is habitat complexity, predator abundance is lowest in both models when the carrying capacity of $F$. lapillum and the density of alternate prey are highest. This suggests that when prey populations reach a certain density threshold, predator growth overwhelms the growth rate of prey populations through bottom up control and the ratio between predator and prey density grows too large to sustain increasing predator abundance, resulting in population crashes. As $P$. colias is a generalist consumer, in the current models predator population can grow without bound as alternate prey are increasingly available and bottom up control is only considered in the growth function of predators. The addition of top-down regulation of 
P. colias would be more biologically realistic as it would incorporate a predator carrying capacity function where the predator's population growth rate slows as its own density increases (Kellner et al. 2010).

Alternate prey abundance was estimated from previous literature on the assemblage of macroinvertebrates within a complex temperate macroalgal habitat and in an adjacent patchy and barren macroalgal habitat. The abundance of molluscs and crustaceans in these habitats were used as estimates due to molluscs and crustaceans being major prey taxa found in P. colias diet (Jiang and Carbines 2002) and assuming they would behave in a similar way as the crustacean, H.rotundifrons used as a model species in experiments. Estimates of F. lapillum were from separate literature that surveyed in Kau Bay, Wellington, the site where model prey were collected from, therefore the relative abundance of alternate prey were scaled to that of F. lapillum. True abundance of F. lapillum, as well as mollusc and crustacean species, surveyed from the New Zealand temperate habitats or the site where model prey were collected from would give more accurate differences in abundance of $P$. colias prey species with and without macroalgal habitat, providing better estimates for the models. The predator growth rate function was relatively simple in the models as it only considered attack rate and conversion efficiency of prey, as well as natural mortality. Refuge availability is a possible driver of different functional responses however, due to the low prey densities and low replication used in the experiment, complete functional response estimates could not be determined and were not examined in the model. Incorporating these functions into the models could potentially capture the consequences of other dynamic drivers such as handling and searching times for the population dynamics of predators.

\section{Chapter 5}




\section{General Conclusions}

\subsection{Overview of Findings}

Habitat complexity can come at the cost of reduced foraging success for predators (Gotceitas and Colgan 1989) but have the trade-off greater prey abundance and biodiversity for communities (Pérez-Matus et al. 2007, Alvarez-Filip et al. 2011). The implications of this trade-off are important in predicting the consequences of complex habitat loss for coastal predators. Macroalgal habitats are threatened by the cumulative effects of climate change and are predicted to suffer reduced habitat quality (Teagle et al. 2017). This study aimed to explore how macroalgal loss impacts the foraging success and productivity of Parapercis colias. Abundance of small fish are generally higher in complex macroalgal habitats (Willis and Anderson 2003, Parsons et al. 2016). Results of this study suggest Forsterygion lapillum use complex macroalgal habitat in particular, both under no predation risk and in response to a potential predator. More sedentary organisms such as Heterozius rotundifrons, also use macroalgal habitats, however they are not as reliant on the complexity of macroalgae specifically to avoid predators, instead using mechanical defence or surrounding substrate for refuge. It is evident that a loss of macroalgal habitat complexity alters the way $P$. colias forages on small fish like $F$. lapillum, which appear to use macroalgae as an important refuge habitat and are consumed less when macroalgal habitat is present. Although abundances of small fish are higher within complex habitat, the physical and visual refuge provided by macroalgae makes it challenging for predators to access and detect prey (Wilson et al. 1990, Wen et al. 2013). Modelling the population dynamics of $P$. colias and F. lapillum with and without habitat complexity show that macroalgal habitats generally support more predators. Although there is a cost of reduced predator foraging efficiency in macroalgal habitats, the higher carrying capacity of $F$. lapillum, coupled with the availability of alternate prey species, support a greater abundance of $P$. colias. The consequence of macroalgal habitat loss for $P$. colias is a higher attack rate of $F$. lapillum which limits the prey population from reaching 
high densities (Crowder and Cooper 1982), preventing $P$. colias from reaching as high of an abundance as in the more complex habitat.

The effect of harvesting on the reduction of stocks and the negative effects of fishing gear on the quality of marine habitats has been an area of increased research (Sainsbury et al. 1993, Turner et al. 1999). Surprisingly complex habitat loss does not appear to exacerbate the impact of fishing intensity on the abundance of $P$. colias, instead habitat complexity and increased refuge availability are more sensitive to fishing pressure and potentially overexploitation. With increasing fishing pressure, there is a greater decrease in the population growth rate with complex habitat, which limits the recovery of $P$. colias and reduces the surplus to fish, without reducing the population. This highlights the need for complex habitat quality and quantity to be considered in the assessment of fishery stocks and their population dynamics, as it is likely to influence the productive output of fisheries (Armstrong et al. 2008).

Demersal fish predators within coastal reef communities of New Zealand, additional to P.colias, primarily stalk small organisms, with small fish and crabs dominating their diets (Russell and Leigh 1983). This study makes the general assumption that the prey species involved are explicitly inhabiting macroalgal habitats. However, it is biologically realistic that both coastal prey fish and mobile macroinvertebrate species that $P$. colias and other demersal predators consume, use multiple areas within macroalgal habitats, and not just within macroalgal blades which this study evaluated. Triplefin species also use understory substrate such as crustose and foliose algae (Pérez-Matus et al. 2016) and also other temperate coastal habitats in New Zealand (Feary and Clements 2006). P. colias use macroalgal reefs, but also other shallow reef habitats dominated by coralline algae, sponge gardens, mollusc beds and cobble or sandy bottom habitats (Schiel and Hickford 2001, Carbines and Haist 2018). This could mean that the productivity of $P$. colias may not be quite as dependent on the complexity of macroalgal habitats, as the study generally assumes. However other coastal biogenic 
habitats in New Zealand, such as mollusc reefs, seagrass meadows, sponge gardens and mangrove forests may suffer similar declines as macroalgal beds in the face of anthropogenic change (Anderson et al. 2019). The same approach used in this study, evaluating the consequences of declining complexity for predators, could potentially be applied to other biogenic habitats and may yield similar results.

\subsection{Limitations}

The study was limited by using artificial macroalgae that did not replicate holdfasts and macroalgal understory. Given the relatively sedentary nature of crabs compared to fish, and the fact that small crabs are known to inhabit holdfasts and crevices within rocky reefs (Anderson et al. 2005), the use of whole macroalgal plants and rocky substrate in mesocosms would be a better replicate of what would realistically be available in natural systems. The mesocosm experiments used prey densities of 2, 4 and 6 individuals to assess predator consumption with and without habitat. These densities were derived from what would be observed in macroalgal habitats in the field, however were clearly not high enough for $P$. colias to reach satiation over the course of the trials. Including a wider range of prey densities would hopefully allow complete functional response curves to be examined for $P$. colias, which would further disentangle how macroalgal habitats affect the consumption rates of $P$. colias.

\subsection{Future Research}

In an attempt to further disentangle the implications of a loss of habitat complexity within macroalgal habitats on the population dynamics of coastal predators, experiments should further explore the effect of macroalgal habitat structure and biomass on predator foraging and prey availability. This study attempted to capture the population dynamics of $P$. colias in the absence or presence of a macroalgae replica and only considering the blades and stipe of the plant. However, we do not know how these dynamics may change with decreasing macroalgal biomass or with 
less structural complexity, such as fewer blades or reduced holdfast complexity. Intermediate levels of habitat complexity have been shown to be optimal for predator consumption rates by offering a higher prey abundance than low complexity habitats and increased prey availability due to less refuge space (Crowder and Cooper 1982, Rogers et al. 2018). By further manipulating macroalgal biomass and complexity and fitting the model used to more certain parameters of prey abundance, predator attack rates and $P$. colias fishing mortality, we could potentially capture the changes in the population dynamics of $P$. colias that have the potential to occur with future simplification of important biogenic habitats. 


\section{References}

Airoldi, L., D. Balata, and M. W. Beck. 2008. The Gray Zone: Relationships between habitat loss and marine diversity and their applications in conservation. Journal of Experimental Marine Biology and Ecology 366:8-15.

Albright, R., B. Mason, M. Miller, and C. Langdon. 2010. Ocean acidification compromises recruitment success of the threatened Caribbean coral Acropora palmata. Proceedings of the National Academy of Sciences of the United States of America 107:20400-4.

Alestra, T., and D. R. Schiel. 2015. Impacts of local and global stressors in intertidal habitats: Influence of altered nutrient, sediment and temperature levels on the early life history of three habitat-forming macroalgae. Journal of Experimental Marine Biology and Ecology 468:29-36.

Almany, G. R. 2004. Does increased habitat complexity reduce predation and competition in coral reef fish assemblages? Oikos 106:275-284.

Alvarez-Filip, L., N. K. Dulvy, J. A. Gill, I. M. Côté, and A. R. Watkinson. 2009. Flattening of Caribbean coral reefs: Region-wide declines in architectural complexity. Proceedings of the Royal Society B: Biological Sciences 276:3019-3025.

Alvarez-Filip, L., J. A. Gill, and N. K. Dulvy. 2011. Complex reef architecture supports more small-bodied fishes and longer food chains on Caribbean reefs. Ecosphere 2.

Anderson, M., C. Diebel, W. Blom, and T. Landers. 2005. Consistency and variation in kelp holdfast assemblages: Spatial patterns of biodiversity for the major phyla at different taxonomic resolutions. Journal of Experimental Marine Biology and Ecology 320:35-56.

Anderson, O., N. Bagley, R. Hurst, M. Francis, M. Clark, and P. McMillan. 1998. Atlas of New Zealand fish and Squid distributions from research bottom trawls. Wellington.

Anderson, T. 2001. Predator responses, prey refuges, and density-dependent mortality of a marine fish. Ecology 82:245-257.

Anderson, T. J., M. Morrison, A. B. Macdiarmid, M. R. Clark, R. D. Archino, D. M. Tracey, D. P. Gordon, G. B. Read, H. Kettles, D. Morrisey, A. Wood, A. M. Smith, M. Page, K. Paul-burke, K. Schnabel, and S. Wadhwa. 2019. Review of New Zealand's Key Biogenic Habitats. Page NIWA Client Report.

Armstrong, C. W., J. Falk-Petersen Armstrong, C. W. Armstrong, and J. Falk-Petersen. 2008. Habitat-fisheries interactions: a missing link?-ICES. Page Journal of Marine Science.

Arnold, M., H. Teagle, M. P. Brown, and D. A. Smale. 2016. The structure of biogenic habitat and epibiotic assemblages associated with the global invasive kelp Undaria pinnatifida in comparison to native macroalgae. Biological Invasions 18:661-676.

Atalah, J., and R. Sneddon. 2016. Lyttelton Harbour and Banks Peninsula shoreline reef ecology: Field survey data report (February 2016). Nelson.

Austin, A., S. Austin, and P. Sale. 1980. Community structure of the fauna associated with the coral Pocillopora damicornis (L.) on the Great Barrier Reef. Marine and Freshwater Research 31:163.

Barbier, E. B. 2017. Marine ecosystem services. Current Biology 27:R507-R510.

Barbraud, C., A. Bertrand, M. Bouchón, A. Chaigneau, K. Delord, H. Demarcq, O. Gimenez, M. G. Torero, D. Gutiérrez, R. OliverosRamos, G. Passuni, Y. Tremblay, and S. Bertrand. 2018. Density dependence, prey accessibility and prey depletion by fisheries drive Peruvian seabird population dynamics. Ecography 41:1092-1102.

Barshaw, D. E., K. L. Lavalli, and E. Spanier. 2003. Offense versus defense: Responses of three morphological types of lobsters to predation. Marine Ecology Progress Series 256:171-182.

Beentjes, M., and M. Fenwick. 2019. Relative abundance, size and age structure, and stock status of blue cod off north Otago in 2018.

Bell, J. D., and M. Westoby. 1986. Abundance of macrofauna in dense seagrass is due to habitat preference, not predation. Oecologia 68:205-209.

Bologna, P. A. X., and R. S. Steneck. 1993. Kelp beds as habitat for American lobster Homarus americanus. Marine Ecology Progress Series 100:127-134.

Boulding, E. G. 1984. Crab-resistant features of shells of burrowing bivalves: Decreasing vulnerability by increasing handling time. Journal of Experimental Marine Biology and Ecology 76:201-223.

Bouwma, P., and B. A. Hazlett. 2001. Integration of multiple predator cues by the crayfish Orconectes propinquus. Animal Behaviour 61:771-776. 
Brady-Campbell, M. M., D. B. Campbell, and M. M. Harlin. 1984. Productivity of kelp (Laminaria spp.) near the southern limit in the Northwestern Atlantic Ocean. Marine Ecology Progress Series 18:79-88.

Bruno, J. F., and M. D. Bertness. 2001. Habitat modification and facilitation in benthic marine communities. Pages 201-218 Marine community ecology. Sinauer Associates:, Sunderland.

Byrnes, J. E., D. C. Reed, B. J. Cardinale, K. C. Cavanaugh, S. J. Holbrook, and R. J. Schmitt. 2011. Climate-driven increases in storm frequency simplify kelp forest food webs. Global Change Biology 17:2513-2524.

Cacabelos, E., C. Olabarria, M. Incera, and J. S. Troncoso. 2010. Effects of habitat structure and tidal height on epifaunal assemblages associated with macroalgae. Estuarine, Coastal and Shelf Science 89:43-52.

Caley, M. J., M. H. Carr, M. A. Hixon, T. P. Hughes, G. P. Jones, and B. A. Menge. 1996. RECRUITMENT AND THE LOCAL DYNAMICS OF OPEN MARINE POPULATIONS. Annual Review of Ecology and Systematics 27:477-500.

Carbines, G. 1998. Determination of movement of blue cod in Southland. Page Final Research Report for Ministry of Fisheries. NIWA, Wellington.

Carbines, G., and V. Haist. 2018. Relative abundance, population structure, and stock status of blue cod off south Otago in 2013. Estimates of pot catchability and size selectivity. New Zealand Fisheries Assessment Report 2018/08. Wellington.

Carbines, G., and J. Mckenzie. 2004. Movement patterns and stock mixing of blue cod in Dusky Sound in 2002. Page New Zealand Fisheries Assessment Report 2004/36. Wellington.

Carr, M. H. 1994. Effects of Macroalgal Dynamics on Recruitment of a Temperate Reef. Ecology 75:1320-1333.

Carroll, J. M., L. J. Jackson, and B. J. Peterson. 2015. The Effect of Increasing Habitat Complexity on Bay Scallop Survival in the Presence of Different Decapod Crustacean Predators. Estuaries and Coasts 38:1569-1579.

Carter, S. K., D. Vodopich, and P. W. Crumrine. 2018. Heterogeneity in body size and habitat complexity influence community structure. Journal of Freshwater Ecology 33:239-249.

Chaves, L. T. C., P. H. C. Pereira, and J. L. L. Feitosa. 2013. Coral reef fish association with macroalgal beds on a tropical reef system in North-eastern Brazil. Marine and Freshwater Research 64:1101-1111.

Chivers, D. P., and R. J. F. Smith. 1998. Chemical alarm signalling in aquatic predator-prey systems: a review and prospectus. Ecoscience 5:338-352.

Clark, K. L., G. M. Ruiz, and A. H. Hines. 2003. Diel variation in predator abundance, predation risk and prey distribution in shallowwater estuarine habitats. Journal of Experimental Marine Biology and Ecology 287:37-55.

Clemente, S., J. C. Hernández, G. Montaño-Moctezuma, M. P. Russell, and T. A. Ebert. 2013. Predators of juvenile sea urchins and the effect of habitat refuges. Marine Biology 160:579-590.

Connell, S. D. 2003. The monopolization of understorey habitat by subtidal encrusting coralline algae: A test of the combined effects of canopy-mediated light and sedimentation. Marine Biology 142:1065-1071.

Crowder, L. B., and W. E. Cooper. 1982. Habitat Structural Complexity and the Interaction Between Bluegills and Their Prey. Ecology 63:1802-1813.

Crowley, P. H. 1978. Effective size and the persistence of ecosystems. Oecologia 35:185-195.

Cushing, D. H. 1995. Population production and regulation in the sea : a fisheries perspective. Cambridge University Press.

Daily, G. C. 2013. Nature's services: Societal dependence on natural ecosystems. Pages 454-461 The Future of Nature: Documents of Global Change. Island Press.

Dayton, P. K. 1985. Ecology of kelp communities. Annual review of ecology and systematics. Vol. 16 16:215-245.

Easterling, D. R., G. A. Meehl, C. Parmesan, S. A. Changnon, T. R. Karl, and L. O. Mearns. 2000. Climate extremes: observations, modeling, and impacts. Science 289:2068-74.

Edwards, M. S., and G. Hernández-Carmona. 2005. Delayed recovery of giant kelp near its southern range limit in the North Pacific following El Niño. Marine Biology 147:273-279.

Endler, J. A. 1984. Progressive background in moths, and a quantitative measure of crypsis. Biological Journal of the Linnean Society 22:187-231.

Engels, B. 2015. XNomial: Exact Goodness-of-Fit Test for Multinomial Data with Fixed Probabilities.

Feary, D. A., and K. D. Clements. 2006. Habitat use by triplefin species (Tripterygiidae) on rocky reefs in New Zealand. Journal of Fish Biology 69:1031-1046.

Feehan, C. J., B. C. Grauman-Boss, R. R. Strathmann, M. N. Dethier, and D. O. Duggins. 2018. Kelp detritus provides high-quality food for sea urchin larvae. Limnology and Oceanography 63:S299-S306. 
Field, L. H. 1990. Aberrant defense displays of the big-handed crab, heterozius rotundifrons (Brachyura: Belliidae). New Zealand Journal of Marine and Freshwater Research 24:211-220.

Filbee-Dexter, K., C. J. Feehan, and R. E. Scheibling. 2016. Large-scale degradation of a kelp ecosystem in an ocean warming hotspot. Marine Ecology Progress Series 543:141-152.

Filbee-Dexter, K., and T. Wernberg. 2018. Rise of Turfs: A New Battlefront for Globally Declining Kelp Forests. BioScience 68:64-76.

Fisheries New Zealand. 2018. Fisheries Assessment Plenary, May 2018: stock assessments and stock status. Wellington, New Zealand.

Forrester, G. E., and M. A. Steele. 2004. PREDATORS, PREY REFUGES, AND THE SPATIAL SCALING OF DENSITY-DEPENDENT PREY MORTALITY. Ecology 85:1332-1342.

Fraser, M. W., G. A. Kendrick, J. Statton, R. K. Hovey, A. Zavala-Perez, and D. I. Walker. 2014. Extreme climate events lower resilience of foundation seagrass at edge of biogeographical range. Journal of Ecology 102:1528-1536.

Fretwell, S. D. 1987. Food Chain Dynamics: The Central Theory of Ecology? Oikos 50:291.

Gochfeld, D. J. 2004. Predation-induced morphological and behavioral defenses in a hard coral: implications for foraging behavior of coral-feeding butterflyfishes. Marine Ecology Progress Series 267:145-158.

Godbold, J. A., M. T. Bulling, and M. Solan. 2011. Habitat structure mediates biodiversity effects on ecosystem properties. Proceedings of the Royal Society B: Biological Sciences 278:2510-2518.

Gotceitas, V., and P. Colgan. 1989. Predator foraging success and habitat complexity: quantitative test of the threshold hypothesis. Oecologia 80:158-166

Grabowski, J. H. 2004. Habitat complexity disrupts predator-prey interactions but not the trophic cascade on oyster reefs. Ecology 85:995-1004.

Graham, N. A. J., and K. L. Nash. 2013. The importance of structural complexity in coral reef ecosystems. Coral Reefs 32:315-326.

Gratwicke, B., and M. R. Speight. 2005. The relationship between fish species richness, abundance and habitat complexity in a range of shallow tropical marine habitats. Journal of Fish Biology 66:650-667.

Gregor, C. A., and T. W. Anderson. 2016. Relative importance of habitat attributes to predation risk in a temperate reef fish. Environmental Biology of Fishes 99:539-556.

Guidetti, P. 2000. Differences among fish assemblages associated with nearshore Posidonia oceanica seagrass beds, rocky-algal reefs and unvegetated sand habitats in the adriatic sea. Estuarine, Coastal and Shelf Science 50:515-529.

Hart, P. J. B., and S. F. Hamrin. 1990. The Role of Behaviour and Morphology in the Selection of Prey by Pike. Pages 235-254 Behavioural Mechanisms of Food Selection. Springer Berlin Heidelberg, Berlin, Heidelberg.

Hassell, M. P. 1978. The dynamics of arthropod predator-prey systems. Monographs in population biology:237.

Hauser, A., M. J. Attrill, and P. A. Cotton. 2006. Effects of habitat complexity on the diversity and abundance of macrofauna colonising artificial kelp holdfasts. Marine Ecology Progress Series 325:93-100.

Hawkins, S. J., H. E. Sugden, N. Mieszkowska, P. J. Moore, E. Poloczanska, R. Leaper, R. J. H. Herbert, M. J. Genner, P. S. Moschella, R. C. Thompson, S. R. Jenkins, A. J. Southward, and M. T. Burrows. 2009. Consequences of climate-driven biodiversity changes for ecosystem functioning of north European rocky shores. Marine Ecology Progress Series 396:245-259.

Hay, C. H. 1990. The distribution of Macrocystis (Phaeophyta: Laminariales) as a biological indicator of cool sea surface temperature, with special reference to New Zealand waters. Journal of the Royal Society of New Zealand 20:313-336.

Hazlett, B. A., and C. McLay. 2000. Contingencies in the behaviour of the crab Heterozius rotundifrons. Animal Behaviour 59:965974.

Hazlett, B. A., and C. McLay. 2005. Responses to predation risk: Alternative strategies in the crab Heterozius rotundifrons. Animal Behaviour 69:967-972.

Heck, K. L., and L. B. Crowder. 1991. Habitat structure and predator-prey interactions in vegetated aquatic systems. Pages 281299 Habitat Structure. Springer Netherlands, Dordrecht.

Heck, K. L., G. S. Wetstone, and G. S. Wetstone. 1977. Habitat Complexity and Invertebrate Species Richness and Abundance in Tropical Seagrass Meadows. Journal of Biogeography 4:135.

Heithaus, M. R., A. J. Wirsing, D. Burkholder, J. Thomson, and L. M. Dill. 2009. Towards a predictive framework for predator risk effects: The interaction of landscape features and prey escape tactics. Journal of Animal Ecology 78:556-562.

Hempson, T. N., N. A. J. Graham, M. A. MacNeil, D. H. Williamson, G. P. Jones, and G. R. Almany. 2017. Coral reef mesopredators switch prey, shortening food chains, in response to habitat degradation. Ecology and Evolution 7:2626-2635. 
Hereu, B., M. Zabala, C. Linares, and E. Sala. 2005. The effects of predator abundance and habitat structural complexity on survival of juvenile sea urchins. Marine Biology 146:293-299.

Hesse, J., J. A. Stanley, and A. G. Jeffs. 2016. Do predatory fish of benthic crustaceans vary between kelp and barren reef habitats in northeastern New Zealand? New Zealand Journal of Marine and Freshwater Research 50:339-357.

Hines, A. H. 1982. Coexistence in a Kelp Forest: Size, Population Dynamics, and Resource Partitioning in a Guild of Spider Crabs (Brachyura, Majidae). Page Source: Ecological Monographs.

Hixon, M. A., and J. P. Beets. 1993. Predation, prey refuges, and the structure of coral-reef fish assemblages. Ecological Monographs 63:77-101.

Holling, C. S. 1959. The Components of Predation as Revealed by a Study of Small-Mammal Predation of the European Pine Sawfly. The Canadian Entomologist 91:293-320.

Holt, R. D. 1987. Prey Communities in Patchy Environments. Oikos 50:276.

Holt, R. D., and M. Loreau. 2002. Biodiversity and Ecosystem Functioning: The Role of Trophic Interactions and the Importance of System Openness. Pages 246-262 The Functional Consequences of Biodiversity. Princeton University Press.

Jacobsen, H. P., and O. B. Stabell. 2004. Antipredator behaviour mediated by chemical cues: The role of conspecific alarm signalling and predator labelling in the avoidance response of a marine gastropod. Oikos 104:43-50.

Jensen, A. L. 1984. Dynamics of fisheries that affect the population growth rate coefficient. Environmental Management 8:135140.

Jiang, W., and G. Carbines. 2002. Diet of blue cod, Parapercis colias, living on undisturbed biogenic reefs and on seabed modified by oyster dredging in Foveaux Strait, New Zealand. Aquatic Conservation: Marine and Freshwater Ecosystems 12:257-272.

Johnson, D. W. 2006. Predation, habitat complexity, and variation in density-dependent mortality of temperate reef fishes. Ecology 87:1179-1188.

Jones, C. G., J. H. Lawton, and M. Shachak. 1994. Organisms as Ecosystem Engineers. Oikos 69:373.

Jones, G. P., M. I. McCormick, M. Srinivasan, and J. V Eagle. 2004. Coral decline threatens fish biodiversity in marine reserves. Proceedings of the National Academy of Sciences of the United States of America 101:8251-8253.

Jørgensen, N. M., and H. Christie. 2003. Diurnal, horizontal and vertical dispersal of kelp-associated fauna. Hydrobiologia 503:6976.

Kats, L. B., and L. M. Dill. 1998. The scent of death: chemosensory assessment of predation risk by prey animals. Ecoscience 5:361394.

Kelaher, B. P., and J. C. Castilla. 2004. Habitat characteristics influence macrofaunal communities in coralline turf more than mesoscale coastal upwelling on the coast of Northern Chile. Estuarine, Coastal and Shelf Science 63:155-165.

Kellner, J. B., S. Y. Litvin, A. Hastings, F. Micheli, J. Peter, and S. Url. 2010. Disentangling trophic interactions inside a Caribbean marine reserve Reviewed work ( s ): trophic 20:1979-1992.

Kiessling, W., and C. Simpson. 2011. On the potential for ocean acidification to be a general cause of ancient reef crises. Global Change Biology 17:56-67.

Kim, J. W., G. E. Brown, I. J. Dolinsek, N. N. Brodeur, A. O. H. C. Leduc, and J. W. A. Grant. 2009. Combined effects of chemical and visual information in eliciting antipredator behaviour in juvenile Atlantic salmon Salmo salar. Journal of Fish Biology $74: 1280-1290$.

Kohn, A. J., and P. J. Leviten. 1976. Effect of habitat complexity on population density and species richness in tropical intertidal predatory gastropod assemblages. Oecologia 25:199-210.

Kovalenko, K. E., S. M. Thomaz, and D. M. Warfe. 2012. Habitat complexity: Approaches and future directions. Hydrobiologia 685:1-17.

Krumhansl, K. A., D. K. Okamoto, A. Rassweiler, M. Novak, J. J. Bolton, K. C. Cavanaugh, S. D. Connell, C. R. Johnson, B. Konar, S. D. Ling, F. Micheli, K. M. Norderhaug, A. Pérez-Matus, I. Sousa-Pinto, D. C. Reed, A. K. Salomon, N. T. Shears, T. Wernberg, R. J. Anderson, N. S. Barrett, A. H. Buschmann, M. H. Carr, J. E. Caselle, S. Derrien-Courtel, G. J. Edgar, M. Edwards, J. A. Estes, C. Goodwin, M. C. Kenner, D. J. Kushner, F. E. Moy, J. Nunn, R. S. Steneck, J. Vásquez, J. Watson, J. D. Witman, and J. E. K. Byrnes. 2016. Global patterns of kelp forest change over the past half-century. Proceedings of the National Academy of Sciences of the United States of America 113:13785-13790.

Langellotto, G. A., and R. F. Denno. 2004. Responses of invertebrate natural enemies to complex-structured habitats: a metaanalytical synthesis. Oecologia 139:1-10.

Lannin, R., and K. Hovel. 2011. Variable prey density modifies the effects of seagrass habitat structure on predator-prey interactions. Marine Ecology Progress Series 442:59-70. 
Leclerc, J. C., P. Riera, M. Laurans, C. Leroux, L. Lévêque, and D. Davoult. 2015. Community, trophic structure and functioning in two contrasting Laminaria hyperborea forests. Estuarine, Coastal and Shelf Science 152:11-22.

Lotka, A. J. 1925. Elements of Physical Biology. Williams and Wilkins.

Luck, G. W., G. C. Daily, and P. R. Ehrlich. 2003. Population diversity and ecosystem services. Trends in Ecology and Evolution 18:331-336.

Luckhurst, B. E., and K. Luckhurst. 1978. Analysis of the influence of substrate variables on coral reef fish communities. Marine Biology 49:317-323.

MacDiarmid, A. B., C. S. Law, M. Pinkerton, and J. Zeldis. 2013. New Zealand Marine Ecosystem Services. Ecosystem services in New Zealand: Conditions and trends:539.

Magnhagen, C., and E. Forsgren. 1991. Behavioural responses to different types of predators by sand goby Pomatoschistus minutus: an experimental study. Marine Ecology Progress Series 70:11-16.

Mann, K. H. 1973. Seaweeds: Their productivity and strategy for growth. Science 182:975-981.

McLay, C. L., and T. A. Osborne. 1985. Burrowing behaviour of the paddle crab Ovalipes catharus (White, 1843) (Brachyura: Portunidae). New Zealand Journal of Marine and Freshwater Research 19:125-130.

Meehl, G. A., T. Karl, D. R. Easterling, S. Changnon, R. Pielke, D. Changnon, J. Evans, P. Y. Groisman, T. R. Knutson, K. E. Kunkel, L. O. Mearns, C. Parmesan, R. Pulwarty, T. Root, R. T. Sylves, P. Whetton, and F. Zwiers. 2000. An Introduction to Trends in Extreme Weather and Climate Events: Observations, Socioeconomic Impacts, Terrestrial Ecological Impacts, and Model Projections *. Bulletin of the American Meteorological Society 81:413-416.

Ménard, A., K. Turgeon, D. G. Roche, S. A. Binning, and D. L. Kramer. 2012. Shelters and their use by fishes on fringing coral reefs. PLOS ONE 7:e38450.

Menge, B. A. 2000. Recruitment vs. Postrecruitment Processes as Determinants of Barnacle Population Abundance. Ecological Monographs 70:265.

Michel, M. J., and M. M. Adams. 2009. Differential effects of structural complexity on predator foraging behavior. Behavioral Ecology 20:313-317.

Milinski, M., and R. Heller. 1978. Influence of a predator on the optimal foraging behaviour of sticklebacks (Gasterosteus aculeatus L.).

Ministry for Primary Industries. 2017. Bladder kelp attached (KBB G).

Munday, P. L. 2004. Habitat loss, resource specialization, and extinction on coral reefs. Global Change Biology 10:1642-1647.

Murdoch, W. W. 1969. Switching in General Predators: Experiments on Predator Specificity and Stability of Prey Populations. Ecological Monographs 39:335-354.

Murdoch, W. W., and A. Oaten. 1975. Predation and Population Stability. Advances in Ecological Research 9:1-131.

Myers, R. A., and B. Worm. 2003. Rapid worldwide depletion of predatory fish communities. Nature 423:280-283.

Norbury, G., and W. van Overmeire. 2019. Low structural complexity of nonnative grassland habitat exposes prey to higher predation. Ecological Applications 29.

Nordberg, E. J., and L. Schwarzkopf. 2019. Predation risk is a function of alternative prey availability rather than predator abundance in a tropical savanna woodland ecosystem. Scientific Reports 9:7718.

Norderhaug, K. M., H. Christie, and S. Fredriksen. 2007. Is habitat size an important factor for faunal abundances on kelp (Laminaria hyperborea)? Journal of Sea Research 58:120-124.

NZ Ministry for Primary Industries. 2014. Fisheries Assessment Plenary May 2014: Volumes 1-3 Stock Assessment and Stock Status. Wellington.

O’Brien, B. S., K. Mello, A. Litterer, and J. A. Dijkstra. 2018. Seaweed structure shapes trophic interactions: A case study using a mid-trophic level fish species. Journal of Experimental Marine Biology and Ecology 506:1-8.

Oaten, A., and W. W. Murdoch. 1975. Switching, Functional Response, and Stability in Predator-Prey Systems. The American Naturalist 109:299-318.

Orth, R. J., K. L. Heck, and J. van Montfrans. 1984. Faunal communities in seagrass beds: A review of the influence of plant structure and prey characteristics on predator-prey relationships. Estuaries 7:339-350.

Pande, A., and J. P. A. Gardner. 2009, March 1. A baseline biological survey of the proposed Taputeranga Marine Reserve (Wellington, New Zealand): Spatial and temporal variability along a natural environmental gradient. Wiley-Blackwell.

Parsons, D. M., I. MacDonald, D. Buckthought, and C. Middleton. 2018. Do nursery habitats provide shelter from flow for juven ile fish? PLOS ONE 13:e0186889. 
Parsons, D., I. Suthers, D. Cruz, and J. Smith. 2016. Effects of habitat on fish abundance and species composition on temperate rocky reefs. Marine Ecoloyg Progress Series 561:155-171.

Patek, S. N., and T. H. Oakley. 2003. Comparative tests of evolutionary trade-offs in a palinurid lobster acoustic system. Evolution 57:2082-2100.

Pécuchet, L., J. R. Nielsen, and A. Christensen. 2015. Impacts of the local environment on recruitment: a comparative study of North Sea and Baltic Sea fish stocks. ICES Journal of Marine Science 72:1323-1335.

Pelejero, C., E. Calvo, and O. Hoegh-Guldberg. 2010, June 1. Paleo-perspectives on ocean acidification. Elsevier Current Trends.

Pérez-Matus, A., L. A. Ferry-Graham, A. Cea, and J. A. Vásquez. 2007. Community structure of temperate reef fishes in kelpdominated subtidal habitats of northern Chile. Marine and Freshwater Research 58:1069-1085.

Pérez-Matus, A., F. Sánchez, J. González-But, and R. Lamb. 2016. Understory algae associations and predation risk influence broadscale kelp habitat use in a temperate reef fish. Marine Ecology Progress Series 559:147-158.

Pérez-Matus, A., and J. S. Shima. 2010. Disentangling the effects of macroalgae on the abundance of temperate reef fishes. Journal of Experimental Marine Biology and Ecology 388:1-10.

Persson, L. 1983. Effects of Intra- and Interspecific Competition on Dynamics and Size Structure of a Perch Perca Fluviatilis and a Roach Rutilus rutilus Population. Oikos 41:126.

Persson, L., J. Andersson, E. Wahlstrom, and P. Eklov. 1996. Size-Specific Interactions in Lake Systems: Predator Gape Limitation and prey Growth Rate and Mortality. Ecology 77:900-911.

Preisser, E. L., D. I. Bolnick, and M. F. Benard. 2005. Scared to death? The effects of intimidation and consumption in predator-prey interactions. Ecology 86:501-509.

R Core Team. 2018. R: A language and environment for statistical computing. R Foundation for Statistical Computing, Vienna, Austria.

Ranåker, L., P. A. Nilsson, and C. Brönmark. 2012. Effects of degraded optical conditions on behavioural responses to alarm cues in a freshwater fish. PLOS ONE 7:e38411.

Reed, D. C., A. Rassweiler, and K. K. Arkema. 2008. Biomass rather than growth rate determines variation in net primary production by giant kelp. Ecology 89:2493-2505.

Rogers, A., J. L. Blanchard, and P. J. Mumby. 2014. Vulnerability of coral reef fisheries to a loss of structural complexity. Current Biology 24:1000-1005.

Rogers, A., J. L. Blanchard, S. P. Newman, C. S. Dryden, and P. J. Mumby. 2018. High refuge availability on coral reefs increases the vulnerability of reef-associated predators to overexploitation. Ecology 99:450-463.

Rosman, J. H., J. R. Koseff, S. G. Monismith, and J. Grover. 2007. A field investigation into the effects of a kelp forest (Macrocystis pyrifera) on coastal hydrodynamics and transport. Journal of Geophysical Research: Oceans 112.

Ross, P. M., S. F. Thrush, J. C. Montgomery, J. W. Walker, and D. M. Parsons. 2007. Habitat complexity and predation risk determine juvenile snapper (Pagrus auratus) and goatfish (Upeneichthys lineatus) behaviour and distribution. Marine and Freshwater Research 58:1144.

Russell, B. C., and R. D. Leigh. 1983. New Zealand Journal of Marine and Freshwater Research The food and feeding habits of rocky reef fish of north-eastern New Zealand The food and feeding habits of rocky reef fish of north-eastern New Zealand. Zealand Journal of Marine and Freshwater Research 17:121-145.

Russell, B. D., J. A. I. Thompson, L. J. Falkenberg, and S. D. Connell. 2009. Synergistic effects of climate change and local stressors: CO2 and nutrient-driven change in subtidal rocky habitats. Global Change Biology 15:2153-2162.

Sainsbury, K., R. Campbell, and A. Whitelaw. 1993. Effects of trawling on the marine habitat on the North West Shelf of Australia and implications for sustainable fisheries management. Pages 137-145 Australian Scoriety for Fish Biology Workshop Victor Harbor, Australia 1992 Bureau Resource Sci Proc.

Samanta, S., R. Dhar, I. M. Elmojtaba, and J. Chattopadhyay. 2016. THE ROLE of ADDITIONAL FOOD in A PREDATOR-PREY MODEL with A PREY REFUGE. Journal of Biological Systems 24:345-365.

Sarnelle, O., and A. E. Wilson. 2008. Type III functional response in daphnia. Ecology 89:1723-1732.

Savino, J. F., and R. A. Stein. 1982. Predator-Prey Interaction between Largemouth Bass and Bluegills as Influenced by Simulated, Submersed Vegetation. Transactions of the American Fisheries Society 111:255-266.

Scharf, F. S., J. P. Manderson, and M. C. Fabrizio. 2006. The effects of seafloor habitat complexity on survival of juvenile fishes: Species-specific interactions with structural refuge. Journal of Experimental Marine Biology and Ecology 335:167-176.

Schiel, D. R. 1990. Macroalgal assemblages in New Zealand: structure, interactions and demography. Hydrobiologia 192:59-76. 
Schiel, D. R., and M. J. H. Hickford. 2001. Biological structure of nearshore rocky subtidal habitats in Southern New Zealand. Science for Conservation:5-54.

Sibly, R. M., and J. Hone. 2002. Population growth rate and its determinants: an overview. Philosophical Transactions of the Royal Society of London. Series B: Biological Sciences 357:1153-1170.

Smolka, J., J. Zeil, and J. M. Hemmi. 2011. Natural visual cues eliciting predator avoidance in fiddler crabs. Proceedings of the Royal Society B: Biological Sciences 278:3584-3592.

Steneck, R. S., M. H. Graham, B. J. Bourque, D. Corbett, J. M. Erlandson, J. A. Estes, and M. J. Tegner. 2002, December 19. Kelp forest ecosystems: Biodiversity, stability, resilience and future. Cambridge University Press.

Stevens, M., and S. Merilaita. 2009. Animal camouflage: Current issues and new perspectives. Philosophical Transactions of the Royal Society B: Biological Sciences 364:423-427.

Strathmann, R. R. 1981. The role of spines in preventing structural damage to echinoid tests. Paleobiology 7:400-406.

Sunday, J. M., K. E. Fabricius, K. J. Kroeker, K. M. Anderson, N. E. Brown, J. P. Barry, S. D. Connell, S. Dupont, B. Gaylord, J. M. HallSpencer, T. Klinger, M. Milazzo, P. L. Munday, B. D. Russell, E. Sanford, V. Thiyagarajan, M. L. H. Vaughan, S. Widdicombe, and C. D. G. Harley. 2017. Ocean acidification can mediate biodiversity shifts by changing biogenic habitat. Nature Climate Change 7:81-85.

Susannah, M., M. I. McCormick, M. D. Mitchell, and M. C. O. Ferrari. 2011. To fear or to feed: The effects of turbidity on perception of risk by a marine fish. Biology Letters 7:811-813.

Teagle, H., S. J. Hawkins, P. J. Moore, and D. A. Smale. 2017. The role of kelp species as biogenic habitat formers in coastal marine ecosystems. Journal of Experimental Marine Biology and Ecology 492:81-98.

Teagle, H., and D. A. Smale. 2018. Climate-driven substitution of habitat-forming species leads to reduced biodiversity within a temperate marine community. Diversity and Distributions 24:1367-1380.

Tegner, M. J., and P. K. Dayton. 2000. Ecosystem effects of fishing in kelp forest communities. ICES Journal of Marine Science 57:579-589.

Terraube, J., B. Arroyo, M. Madders, and F. Mougeot. 2011. Diet specialisation and foraging efficiency under fluctuating vole abundance: a comparison between generalist and specialist avian predators. Oikos 120:234-244.

Thompson, R. C., B. J. Wilson, M. L. Tobin, A. S. Hill, and S. J. Hawkins. 1996. Biologically generated habitat provision and diversity of rocky shore organisms at a hierarchy of spatial scales. Journal of Experimental Marine Biology and Ecology 202:73-84.

Thomson, J. A., D. A. Burkholder, M. R. Heithaus, J. W. Fourqurean, M. W. Fraser, J. Statton, and G. A. Kendrick. 2015. Extreme temperatures, foundation species, and abrupt ecosystem change: an example from an iconic seagrass ecosystem. Global Change Biology 21:1463-1474.

Tilman, D., M. Clark, D. R. Williams, K. Kimmel, S. Polasky, and C. Packer. 2017. Future threats to biodiversity and pathways to their prevention. Nature 546:73-81.

Todd, P. A., R. A. Briers, R. J. Ladle, and F. Middleton. 2006. Phenotype-environment matching in the shore crab (Carcinus maenas). Marine Biology 148:1357-1367.

Toscano, B. J., and B. D. Griffen. 2013. Predator size interacts with habitat structure to determine the allometric scaling of the functional response. Oikos 122:454-462.

Troscianko, J., J. Wilson-Aggarwal, M. Stevens, and C. N. Spottiswoode. 2016. Camouflage predicts survival in ground-nesting birds. Scientific Reports 6.

Turner, S. J., S. F. Thrush, J. E. Hewitt, V. J. Cummings, and G. Funnell. 1999. Fishing impacts and the degradation or loss of habitat structure. Fisheries Management and Ecology 6:401-420.

Unsworth, R. K. F., R. Ambo-Rappe, B. L. Jones, Y. A. La Nafie, A. Irawan, U. E. Hernawan, A. M. Moore, and L. C. Cullen-Unsworth. 2018. Indonesia's globally significant seagrass meadows are under widespread threat. Science of The Total Environment 634:279-286.

Volterra, V. 1926. Variazioni e fluttuazioni del numero d'individui in specie animali conviventi. Mem. Acad. Lincei Roma. 2:31-113.

Walker, B. K., L. K. B. Jordan, and R. E. Spieler. 2009. Relationship of Reef Fish Assemblages and Topographic Complexity on Southeastern Florida Coral Reef Habitats. Journal of Coastal Research 10053:39-48.

Warfe, D. M., and L. A. Barmuta. 2004. Habitat structural complexity mediates the foraging success of multiple predator species. Oecologia 141:171-178.

Weber, M., C. Lott, and K. E. Fabricius. 2006. Sedimentation stress in a scleractinian coral exposed to terrestrial and marine sediments with contrasting physical, organic and geochemical properties. Journal of Experimental Marine Biology and Ecology 336:18-32. 
Wen, C. K. C., M. S. Pratchett, G. R. Almany, and G. P. Jones. 2013. Role of prey availability in microhabitat preferences of juvenile coral trout (Plectropomus: Serranidae). Journal of Experimental Marine Biology and Ecology 443:39-45.

Wernberg, T., G. A. Kendrick, and B. D. Toohey. 2005. Modification of the physical environment by an Ecklonia radiata (Laminariales) canopy and implications for associated foliose algae. Aquatic Ecology 39:419-430.

Werner, E. E., J. F. Gilliam, D. J. Hall, and G. G. Mittelbach. 1983. An Experimental Test of the Effects of Predation Risk on Habitat Use in Fish. Ecology 64:1540-1548.

Wickham et al. 2019. Welcome to the tidyverse. Journal of Open Source Software 4:1686.

Williams, J., F. Stokes, H. Dixon, and K. Hurren. 2017. The economic contribution of commercial fishing to the New Zealand economy. Page Berl.

Willis, T. J., and M. J. Anderson. 2003. Structure of cryptic reef fish assemblages: Relationships with habitat characteristics and predator density. Marine Ecology Progress Series 257:209-221.

Wilson, K., K. Able, and K. Heck. 1990. Predation rates on juvenile blue crabs in estuarine nursery habitats: evidence for the importance of macroalgae (Ulva lactuca). Marine Ecology Progress Series 58:243-251.

Wisenden, B. D. 2000. Olfactory assessment of predation risk in the aquatic environment. Philosophical Transactions of the Royal Society B: Biological Sciences 355:1205-1208. 